\title{
Are Incentive Contracts Rigged By Powerful CEOs?*
}

\author{
Adair Morse, Vikram Nanda, and Amit Seru
}

August, 2009

\footnotetext{
*Acknowledgements:We thank Lawrence Brown, Robert Bushman, Daniel Ferreira, Yaniv Grinstein, Campbell Harvey (the editor), Charles Hadlock, Steve Kaplan, Joshua Rauh, Morten Sorensen, Anjan Thakor, the associate editor, an anonymous referee, and the seminar participants at Arizona State, Alabama, Chicago GSB, Georgia State, Georgia Tech, Michigan, Vienna, Washington St. Louis (Olin), American Finance Association 2006 meetings, European Finance Association 2006 meetings and FEA conference at UNC for their helpful comments and suggestions. The first and third authors are from University of Chicago, Booth School of Business; e-mail: adair.morse@chicagobooth.edu, amit.seru@chicagobooth.edu. The second author is from Georgia Tech; email: vikram.nanda@mgt.gatech.edu. We are responsible for all the errors.
} 


\title{
Are Incentive Contracts Rigged By Powerful CEOs?
}

\begin{abstract}
We argue that powerful CEOs induce their boards to shift the weight on performance measures towards the better performing measures, thereby rigging the incentive part of their pay. The intuition is developed in a simple model in which some powerful CEOs exploit superior information and lack of transparency in compensation contracts to extract rents. The model delivers an explicit structural form for the rigging of $\mathrm{CEO}$ incentive pay along with testable implications that rigging is expected to (1) increase with CEO power; (2) increase with CEO human capital intensity and uncertainty about a firm's future prospects; and (3) negatively impact firm performance. Using measures of CEO power and board independence on a large panel of firms in the U.S., we find support for these predictions. Rigging accounts for at least $10 \%$ of the sensitivity of compensation to performance measures and is increasing in CEO human capital and volatility of a firm's future prospects. Moreover, the portion of incentive pay that is predicted by power is associated with negative subsequent future stock performance of the order of $0.8 \%$ and operating performance of $7.5 \%$ per year. Overall, the results provide evidence against the agency substitution theory and support instead the entrenchment skimming theory. Our results advocate for requiring ex ante disclosure of incentive contract terms.
\end{abstract}




\section{Introduction}

Incentive contracts are generally thought to be one of the governance cornerstones available to a board for aligning managers' interests with those of shareholders (e.g., Holmstrom, 1979). Such contacting may be especially important for inducing CEOs to maximize shareholder value when agency problems are severe (Eaton and Rosen, 1983). In this paper, we cast a negative light on the extent to which incentive contracting can counter agency problems and substitute for good governance arrangements. We argue that when a board is relatively weak, incentive contracting may itself become a source of shareholder value leakage. In particular, we explore the possibility of CEOs influencing their incentive pay by manipulating the manner in which performance is measured.

The intuition is straightforward: Boards use a variety of measures to gauge CEO performance. At the same time, a CEO will often know when her performance along one dimension is going to be stronger than along another dimension. The CEO can use her influence over the board, either directly or indirectly through other insiders, to slant her performance assessment toward the better-performing measures. More specifically, insiders may induce the board to make the CEO's incentive pay more dependent on measures of performance that they know are doing well. The example of Home Depot CEO Robert Nardelli can help fix the idea. A footnote in Home Depot's 2004 proxy statement said that his long-term incentive pay would be calculated by looking at the total return to shareholders over the three-year performance period and comparing that to an established peer group of retailers. By that measure, Nardelli had bombed. Home Depot's stock fell since he took over in December 2000; meanwhile, rival Lowe's shares had soared. In 2005's proxy, however, the footnote changed: he was to receive incentive pay if the company achieved specified levels of average diluted earnings per share a measure by which Home Depot looked far more successful. We term this action of ex post shifting the weight toward better performing measures rigging of the incentive contract.

Given the substantial literature on CEO compensation, it may be helpful to briefly distinguish our notion of contract manipulation from other analyses of CEO rent extraction. Adams, Almeida and Ferreira (2005) find a direct relationship between CEO power and higher compensation. We likewise find evidence that powerful CEOs get paid more. However, our focus is on how CEOs use their power to manipulate incentive contracts and generate rents from what is ostensibly performance based pay - over-and-above the level effect of power on compensation. We build on this existing literature by presenting evidence that power weakens the effectiveness of incentives. Our paper also differs from agency studies looking at the relationship between power and the use of incentive pay versus cash compensation (e.g., Mehran, 1995). Unlike these papers, our theoretical argument is that incentive contracts are, at best, only partially effective in compensating for weak board governance. Moreover, our empirical results imply that to isolate the full effect of actual, nonrigged incentives, it is important to remove portions of incentive pay that are rigged and have the effect of weakening CEO incentives.

Our rigging argument is also quite distinct from the idea that CEOs are compensated 
for luck (Bertrand and Mullainathan, 2001; Garvey and Milbourn, 2006). ${ }^{1}$ The notions are similar to the extent that rigging and pay from luck do not reflect CEO skill or effort and both happen in weak corporate governance environments. Otherwise, the notions are very distinct. In the luck studies, boards pay CEOs for the firm doing well for reasons completely outside the control of the firm: hence, it is the measure of performance (e.g., no adjustment for common industry factors) that is wrong. In our rigging story, on the other hand, insiders undertake active, intentional manipulation to shift weights toward firm-specific measures of performance that are doing better - i.e., the measures of performance may be appropriate, but it is the structure of the incentive contract that is manipulated. Our empirical design distinguishes between these stories and finds strong support for rigging after removing any luck effect.

Finally, rigging is facilitated by the lack of complete disclosure about incentive contract terms ex ante. Hence, we believe that our paper is the first academic study to provide empirical evidence on the need for greater ex-ante disclosure of CEO incentive contracts. We note that there is some recognition of this issue among compensation consultants and in the media. For instance, a recent article in WSJ (15 March, 2006) reports that "Smart companies are increasingly turning to pay for performance. But even that approach has its pitfalls. Performance measures are seldom made public - for competitive reasons, companies say - and are open to manipulation". In the same vein, a recent study by a large compensation consulting firm, Watson Wyatt, indicates the difficulty outside shareholders have in evaluating CEOs performance reward by reporting that $46 \%$ percent of the top 100 US companies did not disclose the actual goals on which they based rewards under their 2006 annual incentive plans.

The paper begins with a simple model that gives us an explicit structural form on the incentive portion of the CEO wage function and guides our empirical tests. A key feature of the model is the notion of a compromised board. We assume that compromised boards act in the interest of CEOs and have few reservations about increasing their compensation - as long as the payments do not reveal the board to be compromised and trigger shareholder outrage a la Bebchuk, Fried and Walker (2002). The prior probability of a compromised board increases with CEO power, though outsiders do not know whether a particular board is compromised or not. In equilibrium, compromised boards conceal their type by using compensation policies that mimic the contracts offered by independent boards.

We make use of a familiar one-period contracting environment in which a risk-averse CEO provides costly but unobservable effort. We extend the model by allowing for a state variable that is observed by the board, though not by outsiders. Independent boards offer the CEO an optimal contract conditional on the state. The set of possible contracts that could be offered by the independent boards forms the complete set of contracts that shareholders expect to see in equilibrium and, thereby, limits the contract choices of a compromised board as well. Despite the pooling in compensation arrangements, we show that asymmetric information and the lack of transparency in CEO compensation arrangements can allow some powerful CEOs

\footnotetext{
${ }^{1}$ Oyer (2004) shows that, in contrast to the pay for luck argument, an optimal contract could allow the CEOs to be compensated for luck type factors due to increase in their outside options.
} 
to rig their compensation without triggering shareholder outrage. Specifically, the flexibility provided to the compromised board in the form of multiple performance measures allows some powerful CEOs to use ex post information to extract rents by manipulating the terms of their incentive based pay. Rigging is thus a yet undiscussed mechanism falling under the concepts of Bebchuk and Fried's (2004) compensation camouflaging.

The model provides us with rich empirical predictions. First, rigging of incentive pay should increase with CEO power. Second, the severity of rigging should increase with the human capital intensity of the CEO and uncertainty about the firm's future prospects, reflecting the extent to which performance weights can be shifted. Finally, firm performance should be decreasing in the amount of rigging. The intuition is that rigging distorts the incentive mechanism and, by weakening the CEO's ex ante incentives, negatively impacts firm performance and value.

To test these predictions, we use a panel of 1,119 firms in the U.S. over the period 1993-2003. Our empirical tests use industry adjusted performance measures to ensure that the effects we document are after controlling for the type of luck factors in Bertrand and Mullainathan (2001) and Garvey and Milbourn (2006). We collect measures for power directly from firm proxies which is richer and more extensive than the readily available dataset choices. This enables us to look at multiple facets of CEO power. For our measures of CEO influence over the board, we create an index of CEO personal power and two measures of board weakness based on the proportion of insiders and the percentage of board appointed by the CEO. Overall, consistent with predictions, we find that CEOs with power rig incentive compensation: The pay of powerful CEOs has greater sensitivity to the better performing of stock returns and return on assets in a given period. Additionally, rigging is significantly higher when the human capital intensity of the CEO and uncertainty about the firm's future prospects is high.

Our rigging results hold under a number of robustness tests and alternative regression specifications. In particular, rigging is apparent in the data using firm fixed effects with alternative dynamic error structures. The magnitude of rigging is economically large and accounts for about $10-30 \%$ of the incentive pay sensitivity to performance. Moreover, we show that rigging is not limited to periods with high stock or accounting performance, and that CEOs rig compensation contracts to take advantage of both stock and accounting returns. In additional tests, we also find that factors associated with stronger governance - such as greater institutional holdings - may moderate the amount of rigging.

Finally, in line with our expectations, we show that rigging is negatively related to future firm performance. To conduct this test, we project incentive compensation onto power variables and economically-motivated variables. We find that the proportion of incentive pay predicted by power variables has a significant negative association with subsequent firm value (Q-ratio), operating return on assets and stock performance. A firm with one standard deviation above mean rigged incentive pay faces a drop of $4.8 \%$ in firm value, $7.5 \%$ in operating return on assets and about $0.82 \%$ drop in four factor risk-adjusted stock returns relative to the sample average, over the subsequent two year period. 
Our work is closely related to the recent literature that documents a steep increase in the level of CEO pay over the last three decades. ${ }^{2}$ Murphy and Zabojnik (2005) and Kaplan and Minton (2007) help to make sense of these increases by demonstrating that a higher expected return to being a CEO compensates for the higher skill level required for the job and for the extra risk (via turnovers) undertaken. This suggests that large pay packages with high demands for performance could be value maximizing for a firm (Kaplan and Rauh, 2008). Consistent with this view, Mehran (1995) find a statistically significant relationship between incentive pay usage and performance. By this reckoning, it is value enhancing that boards have drastically shifted compensation toward performance-based pay in the last few decades.

While compensation has become more sensitive to performance, boards' use of governance and monitoring tools has increased noticeably (Huson, Parrino, and Starks, 2001). Hartzell and Starks (2003) document higher pay-for-performance sensitivity in companies with greater institutional owner monitoring, and Core, Holthauser and Larcker (1999) document an increase in performance from the portions of compensation predicted by board and ownership structures. Taken together, it seems that a need for higher, incentive-based compensation coincides with a greater benefit from countering agency concerns through monitoring However, it may be that any benefits from more and higher incentive pay are not felt equally across firms. The concern is that even if the current environment warrants an increase in CEO compensation, particularly of the incentive pay form, CEOs who have power will be opportunistic. Bebchuk and Fried (2004) argue, for instance, that CEOs have considerable sway over their boards and use it to secure excessive compensation. ${ }^{3}$ Two theories deal directly with the relationship between $\mathrm{CEO}$ power and compensation in the cross-section of firms.

The first theory builds on the optimal contracting literature that incentive contracts mitigate agency problems (e.g., Holmstrom (1979); Grossman and Hart (1983); Eaton and Rosen (1983)). This agency-substitution theory emphasizes the role of CEO incentive pay as a substitute for monitoring by the board, consistent with the trends documented in Huson et al (2001) and Hartzell and Starks (2003). Critical for this theory is that incentive pay will be especially prevalent for entrenched, powerful CEOs - those that are difficult for boards to monitor. Evidence on the substitution theory as it relates to CEO power is somewhat mixed, however. Muslu (2003) finds that the equity percentage of pay decreases with CEO power as measured by outside representation on the board. On the other hand, Gomez-Mejia, Tosi and Hinkin (1987) show that compensation sensitivity to performance is higher for CEOs in firms with a dominant outside block holder, and Mehran (1995) finds a positive relation between equity

\footnotetext{
${ }^{2}$ e.g., Bebchuk and Fried (2004), Jensen, Murphy and Wruck (2004) and Bebchuk and Grinstein (2005)

${ }^{3}$ Committee members appointed by the CEO can be swayed in their deliberations concerning executive compensation by notions of reciprocity (Main, O'Reilly and Wade (1995)) and indebtedness (Hermalin and Weisbach (1988)). Until recently CEOs could use their position to influence the compensation committee directly via insider participation on the committee (Shivdasani and Yermack (1999); Bertsch, Leahey and Haun (1998); Newman and Mozes (1999)). Even without direct insider representation, CEOs can exert influence via the reciprocal actions of "interlocking" boards (Hallock (1997)). Directors may, in general, have little incentive to curb CEO compensation and may be less than fully cognizant of the costs of option and stock grants (Murphy, 1999).
} 
percentage and CEO power.

A second theory regarding CEO power and compensation is that much of the increases in CEO pay reflects CEOs using power to skim rents from the firm. Rent skimming may be direct transfers of compensation as in Adams et al. (2005) or may be disguised compensation in the form of incentive pay. Disguised compensation is described as compensation camouflage by Bebchuk and Fried (2004) or symbolic compensation by Zajac and Westphal (1998). Lie (2005), Lie and Randall (2007), Narayanan and Seyhun (2006) and Yermack (1997) find, for instance, that executive options are often backdated to hide direct cash giveaways to CEOs and senior management.

Our paper fits into this genre by arguing that while better performing CEOs might be getting higher pay for performance, certain CEOs are able to extract rents by camouflaging their compensation as incentive pay, with the distortion in CEO incentives leading to a reduction in firm value. In this respect, our results provide evidence against the agency substitution theory and support instead the entrenchment skimming theory. While explicit disclosure of ex ante incentive pay contracts would directly eliminate the possibility of rigging, our results suggest that strong governance along other dimensions may also alleviate the rigging of incentive contracts.

The paper is organized as follows. Section II describes the simple model and discusses the hypothesis and our three predictions. Section III discusses the data and the variables used in the empirical analysis. Section IV presents the summary statistics, while Section V outlines the empirical strategy. Section VI and Section VII present empirical results and Section VIII concludes.

\section{Model and Hypothesis}

\section{II.A Basic Set-up}

In this section we develop a simple equilibrium model of rigging. In contrast to models of luck (e.g., Bertrand and Mullainathan, 2001; Garvey and Milbourn, 2006) in which pay-forperformance plans compensate CEOs for luck factors outside the CEO's control (e.g., industry shocks), our model demonstrates how CEOs can manipulate the terms of their performance contract to increase compensation. In the absence of contract disclosure, some powerful CEOs can use ex post information and extract rents by making the incentive pay more sensitive to performance measures they know are doing well. The model delivers an explicit structural form for the rigging of the incentive portion of the CEO wage function. We later use this structural form to guide our empirical tests.

We start by assuming that the boards of directors can be of two types - independent boards seeking to maximize shareholder wealth or compromised boards subject to influence by powerful CEOs. Compromised board attempt to maximize the CEO's compensation, as long 
as they can do so without triggering shareholder outrage. We assume that firms are owned by large numbers of small shareholders who, along with other outsiders, are uninformed about the nature of specific boards, i.e., whether the boards are independent or compromised. We assume that CEOs have power, captured by the parameter $\theta$. Outsiders have access to some public information about a CEO's power such as the CEO's tenure or whether the CEO is also board chairman. For them, $\theta$ represents the prior probability with which the firm's board is compromised. Correspondingly, $(1-\theta)$, represents the prior probability with which the board is independent. The range of $\theta$ is taken to be such that outsiders have no incentive to bear the cost to investigate or replace the board without additional information. ${ }^{4}$

Board members derive benefits from their position and will avoid actions that may precipitate their removal. We assume that boards that are revealed to be compromised trigger shareholder outrage, leading to their eventual ouster through a proxy fight or by takeover. Hence, in equilibrium, compromised boards have the incentive to mimic the actions of independent boards and avoid revealing their type. We analyze such a pooling equilibrium specifically, one in which all boards pool by offering similar types of compensation. Since independent boards have no reason to deviate from offering contracts they consider optimal, the only contracts observed in the pooling equilibrium will be ones that an independent board might choose. ${ }^{5}$

To discuss rigging, we make use of a familiar one-period contracting environment in which a risk-averse CEO provides costly but unobservable effort. We extend the model by allowing for a state variable that is observed by the board, though not by outsiders. Independent boards would offer the CEO an optimal contract conditional on the state that is realized. The set of possible contracts that could be offered by the independent boards forms the complete set of contracts that shareholders expect to see in equilibrium and, thereby, limits the contract choices of a compromised board as well. Powerful CEOs, however, seek to exploit the contract choice in the best way they can. The possibility of contract manipulation arises in our setting because the details of the initial CEO contracts, as is the usual case in practice, are not transparent. ${ }^{6}$ For instance, typical of the lack of explicit disclosure, Walt Disney in its compensation guidelines mentions that the compensation committee will "set individual performance measures and

\footnotetext{
${ }^{4}$ This is obviously a very simplified view of how compensation is set. Conversations with industry experts suggest that CEO compensation in most of the large firms is set by board members on the compensation committee working with an external compensation consultant. The incentive pay is mostly based on multiple measures of performance and the board typically has large discretion on what the final incentive award of the CEO is since the exact terms are seldom made public. We should also note that despite the presence of compensation consultants, there is reason to believe that rigging might still occur. In particular, as was noted by Waxman House Oversight Committee, roughly half of Fortune 250 companies used outside compensation consultants that had incentives to comply with the CEO as they were also providing much more lucrative services - such as employee benefits administration, human resources management and actuarial services - at the same time.

${ }^{5}$ The set of pooling contracts can be viewed as defining the "norm" - with the boards that violate the norms on CEO compensation being subject to punishment and removal.

${ }^{6}$ This assumption that the contracts are not transparent can be relaxed and, so long as there is some uncertainty about contract terms, we expect rigging to survive.
} 
goals for each executive" without mentioning what the measures or the goals are. Similarly, Bristol-Myers Squibb Company compensation guidelines note that "individual performance was a primary determinate of incentive compensation" but the company does not describe how that measure translated to the pay it handed out.

\section{II.B State-Contingent Contracts Offered by Independent Boards}

Consider a familiar principal-agent problem in a one-period setting with dates $t=\{0,1\}$. At the initial date $t=0$, an independent board, acting as a risk-neutral principal on behalf of the firm's shareholders, offers the CEO one of two optimal compensation contracts. The choice of the optimal contract depends on the realization of a state variable $s \in\{1,2\}$. The two states are equally likely, with the realization being observed only by firm insiders at $t=0$. The firm's CEO is risk-averse, and her choice of effort level affects firm value. The CEO, facing an independent board, accepts any contract so long as she obtains an expected utility that is not less than her reservation wage, denoted by $U_{R}$.

The CEO's effort level is denoted by a continuous variable $e$, where the effort comes at a personal cost to the CEO of $\frac{1}{2} \mu e^{2}$ where $\mu>0$. The firm's cash-flows, $V(e)$, are realized at date $t=1$, where $V=\lambda e$ with $\lambda>0$. The $\lambda$ parameter is a measure of the CEO's human capital and reflects the importance of the CEO's input and effort to firm value. We make the standard assumption that the CEO's effort level is not observable (Holmstrom, 1979). However, there are two publicly observable measures of the firm's output at date $t=1$, denoted by $Y_{1}$ and $Y_{2}$, that are used by the board to offer the CEO an optimal incentive contract. We restrict ourselves to contracts that are linear in $Y_{1}$ and $Y_{2}{ }^{7}$

The two performance measures provide noisy measures of the manager's effort level, where the relation is affected by the realization of the state variable $s$. An example of this may be when, in one state, the CEO's effort is better reflected in stock prices - while, in the other state, the CEO's effort is more related to performance measures such as accounting earnings. ${ }^{8}$ The assumption we make is that:

$$
\begin{gathered}
Y_{1}=\eta_{1 s} e+u_{1} \\
Y_{2}=\eta_{2 s} e+u_{2} .
\end{gathered}
$$

The realization of state $s$ affects the relation between effort and the output measures through

\footnotetext{
${ }^{7}$ In our simple one period model the optimal contract will be based on the one period performance measures $Y_{1}$ and $Y_{2}$. However, in a more general setting with multiple periods, it may be optimal for the compensation in any period to be based on current as well as lagged performance. For instance, if there is learning about CEO ability, performance in one period will affect compensation in future periods as well. Even without learning, it may be optimal for the rewards for a strong performance to be given out over more than one period as a way, for instance, to induce the CEO to stay with the firm (similar to the effect that having a vesting period for pension benefits reduces employee turnover). Also note that while we simplify the setting and take two performance measures, the basic insight of the model is robust to using more than two performance measures.

${ }^{8}$ This may happen, for instance, when stock prices are driven mainly by broader economic concerns and less reflective of managerial effort per se.
} 
the $\eta$ term - where the first subscript on $\eta$ refers to the output measure and the second to the state. Specifically, in state 1, the impact of effort on the first output measure, $Y_{1}$ is greater than its impact on $Y_{2}$ with $\eta_{11}=1$ and $\eta_{21}=\delta$, where $0<\delta<1$. On the other hand, in state 2 , effort has a greater impact on the second output measure, $Y_{2}$ with $\eta_{12}=\delta$ and $\eta_{22}=1$. As indicated, the output measures are noisily related to effort on account of $u_{1}, u_{2}$ that are taken to be $i . i . d$ normal variables, $u_{1}, u_{2} \sim N\left(0, \sigma_{u}^{2}\right) .{ }^{9}$ While outsiders do not observe the realization of $s$, it is assumed that they know its distribution and relation to output measures. We now characterize the two state-contingent optimal contracts that an independent board would offer.

We take the CEO to be risk-averse with a mean-variance utility function in date $t=1$ wealth, $w$. For a stochastic payoff of $w$ at $t=1$, the CEO's expected utility is given by: ${ }^{10}$

$$
U(\tilde{w})=E(w)-\frac{1}{2} \gamma \sigma_{w}^{2}
$$

Here, $E(w)$ and $\sigma_{w}^{2}$ are the expected value and variance of $w$, respectively, and $\gamma$ is a riskaversion parameter.

For the moment, let us fix the state to be $s=1$. We denote the linear incentive contract offered to the CEOs as follows:

$$
\alpha_{0}+\beta_{1} Y_{1}+\beta_{2} Y_{2}
$$

Here, $\alpha_{0}$ is the 'base pay' which is determined by the condition that the CEO's expected utility from the contract not be less than her reservation wage $U_{R}$. Given our assumptions that the two states are symmetric, $\alpha_{0}$ will not depend on the state realization. The loadings $\beta_{1}$ and $\beta_{2}$ provide the $\mathrm{CEO}$ with incentives to provide effort. In this setting, we obtain the optimal weights on the performance measures by finding the contract that maximizes payoff to shareholders, while keeping the CEO's expected utility at its reservation level. It is straightforward to show that the optimal weights in state $s=1$ are given by:

$$
\begin{array}{r}
\beta_{1}^{*}=\frac{\lambda}{\left(1+\delta^{2}\right)+\gamma \mu \sigma_{u}^{2}} \\
\beta_{2}^{*}=\delta \beta_{1}^{*} .
\end{array}
$$

Equation (3) implies that the optimal contract, as we would expect, puts greater weight on the more informative signal $\left(\beta_{1}^{*}>\beta_{2}^{*}\right)$. For exposition purposes we denote $\bar{\beta}=\beta_{1}^{*}=\frac{\lambda}{\left(1+\delta^{2}\right)+\gamma \mu \sigma_{u}^{2}}$ and $\underline{\beta}=\delta \bar{\beta}$. Hence, in state $s=1$, the optimal contract can be characterized in terms of the

\footnotetext{
${ }^{9}$ The assumption that $u_{1}, u_{2}$ are independent simplifies the expressions. However, assuming a positive correlation (less than 1) does not qualitatively affect any of the results. In the limit, if the noise in the two performance measures is perfectly correlated, the problem degenerates to one in which the manager's effort $e$ is perfectly revealed since $Y_{1}-Y_{2}=(1-\delta) e$. If the correlation is sufficiently high (though less than 1 ), it is possible that optimal contract will one in which the less informative of the performance measures is used for signal extraction rather than for providing effort incentive i.e., the optimal contract will place a negative loading on the performance measure that is less correlated with the effort level.

${ }^{10}$ Given our normal distribution assumptions, the mean-variance objective is equivalent to assuming an exponential utility function in end of period wealth.
} 
weights on the two performance measures, $\{\bar{\beta}, \beta\}$. Correspondingly, in state $s=2$, the optimal contract is given by: $\{\underline{\beta}, \bar{\beta}\} .{ }^{11}$

We assume that outsiders are fully aware of the two state-dependent optimal contracts and, being unaware of the state $s$, anticipate that independent boards will set incentive weights on the CEO's compensation contract $\left\{\beta_{1}, \beta_{2}\right\}$ to be either $\{\bar{\beta}, \beta\}$ or $\{\underline{\beta}, \bar{\beta}\}$. The CEO contracting arrangements are assumed to be opaque, and outsiders become aware of the actual compensation contract only at date $t=1$. Hence, a compromised board that does not want to be identified must choose one of the two compensation contracts that an independent board might offer. The compromised board can, however, select between the two contracts - and choose the one that produces the larger ex post compensation.

\section{II.C Ex post Manipulation by a Compromised Board}

We now discuss the compensation payments by a compromised board. We assume that a compromised board decides the terms of the compensation at an intermediate date when it receives information about the outcome that is likely to occur. This is well after the CEO has exerted her effort, and thus the contract serves no incentive function. In our set-up, the board has the ability to lie about the state: the board can, for instance, claim that the state is, say, $s=1$ while it may actually be $s=2$.

We can now see the impact of compensating the CEO on the basis of ex post information. If at $t=0$ the board and CEO know the state is $s=1$, the optimal contract requires $\beta_{1}=\bar{\beta}$ and $\beta_{2}=\beta$. For a compromised board, the compensation will, however, depend on the information received at some intermediate date about the realizations of $Y_{1}$ and $Y_{2}$. Two possible cases depending on what the realizations of $u_{1}$ and $u_{2}$ are: (i) $Y_{1} \geq Y_{2}$ and (ii) $Y_{2}>Y_{1}$.

(i) For the case when $Y_{1} \geq Y_{2}$, a compromised board has no reason to change contract terms since the payoff under the optimal contract is already the highest the CEO can obtain. The compensation to the CEO will be:

$$
\alpha_{0}+\bar{\beta} Y_{1}+\underline{\beta} Y_{2}
$$

(ii) When $Y_{2}>Y_{1}$, however, it is easy to see that the payoff to the CEO at $t=1$ would be greater if the compensation contract was switched to the one corresponding to state $s=2$ - which placed a greater weight on the better performing measure $Y_{2}$. A switch in contract terms would result in the CEO's compensation being:

$$
\alpha_{0}+\bar{\beta} Y_{1}+\underline{\beta} Y_{2}+(\bar{\beta}-\underline{\beta})\left\{Y_{2}-Y_{1}\right\}
$$

As we have discussed, the probability with which a board is compromised is given by the

\footnotetext{
${ }^{11}$ The expression for $\alpha_{0}$, not important for our purposes, is given by: $U_{R}-(\bar{\beta}+\delta \underline{\beta}) e^{*}+\frac{1}{2} \mu\left(e^{*}\right)^{2}+\frac{1}{2} \gamma\left[\beta_{1}^{2} \sigma_{u}^{2}+\right.$ $\left.\beta_{2}^{2} \sigma_{u}^{2}\right]$, where $e^{*}$ is the CEO's optimal effort level.
} 
parameter $\theta$. Hence, with $Y_{2}>Y_{1}$, the anticipated compensation for a CEO with power $\theta$ can be expressed as:

$$
\alpha_{0}+\bar{\beta} Y_{1}+\underline{\beta} Y_{2}+\theta(\bar{\beta}-\underline{\beta})\left\{Y_{2}-Y_{1}\right\} .
$$

This expression is intuitive. The first three terms correspond to the payoff under the optimal contract in the state $s=1$. The fourth term represents additional rents paid to the CEO and is comprised of three pieces. First, since the board is compromised with probability $\theta$, expected rents are proportional to this power parameter. Second, the rents are also proportional to the difference between the realization of $Y_{2}$ and $Y_{1}$ since this measures the 'ex post size of the opportunity'. Finally, the additional rents are proportional to the difference in contract weights, i.e., the extent to which performance weights can be shifted, $(\bar{\beta}-\underline{\beta})$. From equations (2) and (3), it is easy to see that the difference in contract weights is increasing in $\lambda$ which represents the CEO's human capital intensity and $(1-\delta)$ which is the differential impact of CEO effort on the two performance measures.

Combining the two cases, conditional on $Y_{1}$ and $Y_{2}$, expected CEO compensation when the board is compromised with probability $\theta$ is given by:

$$
\alpha_{0}+\bar{\beta} Y_{1}+\underline{\beta} Y_{2}+\theta(\bar{\beta}-\underline{\beta}) * \operatorname{Max}\left\{0, Y_{2}-Y_{1}\right\}
$$

The payments to the CEOs when the state is $s=2$ can be similarly expressed. We can now state the Propositions below. The proofs are in the appendix.

Proposition 1: In the presence of CEO power $\theta, C E O$ compensation $W$ will be related to performance measures $Y_{1}, Y_{2}$ by an equation of the form:

$$
W=\alpha_{0}+\hat{\hat{\beta}} Y_{1}+\hat{\hat{\beta}} Y_{2}+\Delta \operatorname{Max}\left\{Y_{1}, Y_{2}\right\},
$$

where $\Delta$ is:

1. Increasing in CEO power $\theta$,

2. Increasing in $\lambda$, the importance of CEO effort to firm value,

3. Increasing in the differential impact of CEO effort on the two measures, $(1-\delta)$.

\section{Proof: See Appendix}

In terms of the effect of rigging on firm value, we can state the following proposition:

Proposition 2: CEO power, will result in loss in firm value. The loss in value will be related to factors that increase $\Delta$, the loading on $\operatorname{Max}\left\{Y_{1}, Y_{2}\right\}$.

Proof: See Appendix

The intuition for the proposition is as follows. CEO power results in ex post switching away from the ex ante optimal contact. This in turn adversely affects the CEO's ex ante incentives 
to provide the optimal level of effort - since the possibility of contract switching reduces the sensitivity of her expected compensation to the effort provided. As a consequence, firm value suffers. This intuition is similar to that developed, for instance, in Acharya et al. (2000) about the impact of resetting executive options on ex ante incentives.

An issue that is worth addressing at this stage is whether our simple, one period model with rigging could be extended to a multi-period setting, in which outside investors observed the firm's performance and CEO compensation over time. This extension helps assess if investors would detect rigging right away and seek to dislodge the $\mathrm{CEO}$ and the board. We believe not. Our view is that learning about rigging would be gradual and that the model could be extended to allow for updating of the power parameter $\theta$ over time. In this we follow the logic of models with dynamic learning (Holmstrom, 1982; Diamond, 1989). In a multi-period version of our model we expect that as outsiders observe the compensation received by the CEO - for instance, if they observe that the ex-post rewards favor the CEO more than would be expected under an independent board, their posterior about $\theta$ will gradually increase. In equilibrium, the speed at which the learning takes place may not be exogenous. The reason is that we expect that there will be mixed strategies in a multi-period setting - in which the rigging is only done with some probability by compromised boards, making it harder for outsiders to detect whether a board is compromised. In other words, it may take a large number of periods for outsiders to be sufficiently confident that board is compromised in a particular firm and to take costly actions to challenge the CEO and board.

In the model we have not explicitly modeled the possible role of external monitors e.g., institutional investors and the market for corporate control in moderating the rigging of CEO incentive pay. A simple way to incorporate this in our set-up is by allowing for the possibility that stronger governance may reduce the likelihood with which a compromised board can successfully rig CEO pay. Specifically, let governance be parametrized by an index $\Gamma<1$, where higher values represent stronger governance. The assumption is that in a firm with a governance level of $\Gamma$ and a compromised board, CEO incentive pay can be rigged only with a probability of $1-\Gamma$. It is straightforward to show that the introduction of such a governance parameter in the model would not affect the form of equations (4) and (5), with the proviso that $\theta$ would be replaced by $\theta^{\prime}=(1-\Gamma) \theta$. The testable prediction is that $\Delta$ in equation (5) would be expected to be lower for higher levels of governance.

We now briefly state the predictions of the model that form the basis of our empirical tests. First, following the first proposition, we examine if the compensation received by powerful CEOs is more sensitive to the performance measure that does better ex post. Next, we test if this sensitivity is increasing in the human capital intensity of the CEO and uncertainty about the firm's prospects; and whether stronger governance tends to moderate these effects. Finally, based on the second proposition, we examine if, on average, firms in which powerful CEOs rig their incentive pay are associated with lower performance. 


\section{Data}

Our CEO compensation data come from Execucomp, which provides information for 2,348 unique firms over the 1992-2003 period. Execucomp decomposes compensation into salary, bonus, equity-based pay (using Black-Scholes values for option grants), and other compensation. We primarily focus our analysis on total compensation because rigged compensation by CEOs may take the form of cash compensation (salary and bonus) or stock and option grants. Since different forms of compensation may not be fully fungible, we also estimate rigging using only cash compensation and compare the results with the rigging estimated in total compensation.

Our analysis follows the well established compensation literature in controlling for human capital predictors of compensation. It has been argued that asset size and volatility proxy for the complication of the job; hence a positive relation between these proxies and pay might reflect compensation for CEO skill (Murphy and Zabojnik, 2005; Eaton and Rosen, 1983). In the literature, the length of tenure in the CEO job is also positively related to compensation, possibly reflecting compensation for the accumulation of specific human capital. We control for these human capital predictors of compensation using the natural log of assets $(\operatorname{Ln}($ Assets $))$, the prior 5-year average Black-Scholes volatility (Volatility) and quadratic terms for tenure (Tenure) from Execucomp. ${ }^{12}$

To gauge firm performance, we rely mainly on two measures - accounting returns (reflecting short term performance) and stock returns (reflecting long term performance). Banker and Datar (1989), Sloan (1993), Bushman et al. (1996) and Core et al. (2003) show that the combination of return on assets and return on stock holdings nearly span the sensitivity of compensation to performance. We show that the results are qualitatively similar when we include a third measure of performance, operating earnings per share, in our estimation.

Measurement of power is fundamental for our inference. For our purposes, the term power is treated as the power to influence the decisions made by the board, above and beyond the effect of ownership rights of control. To better isolate our notion of power, we control for CEOs' ownership share (Gordon, 1940; Gomez-Mejia, Tosi, and Hinkin, 1987; Himmelberg, Hubbard and Palia, 1999). Following Himmelberg et al., we allow for nonlinearities in ownership (SharesOwned) to affect compensation by including the square of share ownership in the estimations. We also control for the value of CEOs' exercisable option holdings since they have been found to be important in explaining annual pay (Adams, Almeida and Ferreira, 2005).

An important point is that our model does not suggest what form CEO power should take for incentive contract rigging to occur. Consequently, in our tests examining the effect of

\footnotetext{
${ }^{12}$ Execucomp's reporting of CEO start date results in negative tenures in approximately $7.5 \%$ of the cases. For these cases, we assign tenure equal to the time lapse since the person joined the firm times the average percent of time spent in the firm prior to CEO status by year. This removes 121 of the 777 missing values. For the other 656 observations, we assign the 33 percentile tenure period ( 3 years) to be conservative. The results do not change when we use other assigning algorithms.
} 
power on incentive pay, we study several of the power measures that have been considered in the literature. Because the concept of CEO power is not easily defined along a single dimension, showing that our results hold across different measures is useful in documenting the robustness of our results.

We construct three measures of CEO power. Our first measure of power, following Adams et al. (2005), is an index (PowerIndex) of CEO personal influence over the board. We construct PowerIndex using Execucomp data by giving the CEO one point for being the chair of the board and two points for being the chair of the board and also the president of the company. The CEO's dual role of chief executive and chair implies that she can direct board initiatives. When the CEO is also the company president, the CEO has not allowed the board to have an in-training successor they might tap if disagreement with the CEO ensues (Adams et al. 2005).

The second and third measures of CEO power capture the weakness of the board to be in a position to counter the CEO. All else equal, relatively more insiders, whose incentives are presumably aligned to support CEO initiatives, should be associated with more power for the CEO (Hermalin and Weisbach, 1988). ${ }^{13}$ To construct insider percentage (Insider\%), we count the director names for each firm in Compact Disclosure's proxy statement data for each year and match this board size to the count of insiders in Execucomp serving on the board.

The third measure is constructed to capture the obligation a board member may feel toward the CEO for being appointed during the CEO's tenure (Westphal and Zajac, 1995; Shivdasani and Yermack, 1999). The higher the percentage of such board members, the more likely it is that the CEO will be able to exert power over the board members. We construct the percentage of the board appointed during the CEOs tenure (\% Appointed) using data on when each board member was appointed in the Compact Disclosure data. Because we do not know the precise dates of $\mathrm{CEO}$ and board appointment within the year, we exclude the appointments during the CEO hiring year. ${ }^{14}$

The second prediction of our model suggests that rigging will be more severe with a larger importance of human capital in firm value creation and with a higher degree of uncertainty in the firm's future prospects. To proxy for CEOs' human capital intensity, we employ several variables. First, we use R\&D intensity (R\&D expenditure to sales ratio) of the firm to capture the specific content of CEOs' human capital. The objective of this proxy is to capture the ease with which the firm could replace the current CEO's knowledge. The higher the research intensity, the more difficult it should be to find a replacement CEO with similar specific human capital. Second, we proxy for CEOs' human capital intensity by complexity of the business

\footnotetext{
${ }^{13}$ Rosenstein and Wyatt (1990) find that the appointment of outside directors produces a positive stock price response, on average. Weisbach (1988) documents that poor stock-price performance increases the probability that the CEO will be replaced; this probability increases further with the percentage of outside directors.

${ }^{14}$ Our results are qualitatively similar if we do not exclude these appointments. Also, we were initially concerned that appointments made during the first few years of a CEO's tenure might not be favorable to the new CEO if she is yet to acquire sufficient power to influence the nominations. Our results look very similar when we exclude the early year appointments from our defining of this variable.
} 
that she is handling. We identify a more complex business by the different segments/lines of business the firm is operating in and by the employees to sales ratio of the firm. To proxy for the uncertainty of future prospects, we use the industry variance of stock returns constructed based on Campbell et al. (2001). A higher industry variance implies more uncertainty regarding the industry's long term prospects.

In additional tests we examine if factors that strengthen firm governance tend to mitigate CEO power and the degree of contract rigging. To this end, we construct two measures governance: the first is the proportion of institutional investors. We use proxy statement data in Compact Disclosure to obtain institutional holdings data. As our second governance measure, we use the IRRC/Gompers, Ishii, and Metrick (2003) governance index. To fill in the missing years, we interpolate the governance index from IRRC. The extent of incentive contract rigging is estimated for the sample split on the basis of these governance measures.

Our sample from Execucomp contains 10,409 CEO year observations over 1992-2003. When we match measures of human capital and power, our sample size reduces to a range of 8,263 to 5,474 observations covering 1,192 to 1,027 firms, depending on the power measure used.

\section{Sample Statistics}

Figure 1 presents the raw distributions (histograms) of the three power measures. PowerIndex ranges from 1 to 3 , symmetrically around a median and mean of 2 . There are a significant number of CEO observations at each PowerIndex level with $27 \%$ and $28 \%$ of the observations at values of 1 and 3 respectively.

Insider \% consists of two parts - the total number of directors and the number of inside directors. The mean (median) number of directors is 10.62 (10), in line with prior literature, which finds the median number of directors to be 11 (Lehn, Patro and Zhao, 2003). The mean and median number of insiders on the board is 2 , with a range from 0 to 8 . The mean (median) Insider \% is $0.225(0.182)$. In Lehn et al.'s time series, the median insider percentage falls from 0.43 in 1935 to 0.13 in 2000, in line with our calculations.

The final histogram depicts $\%$ Appointed. The mean and median are approximately the same with $55 \%$ of board members being appointed by the then current CEO. However, the distribution is far from symmetric. Fifteen percent of firm-years have CEOs who have not appointed any board members, and over double this amount, about $40 \%$, are overseeing a firm in which all the board members then serving have been appointed during the CEO's tenure. One might worry that there will be a mechanical positive relationship between this measure and tenure of the CEO since more board members are likely to be appointed as the CEO tenure increases. Though it is indeed true that there is a positive relationship between the two measures, the correlation of $\%$ Appointed on tenure is 0.68 , indicating that about a third of the information of \% Appointed is not explained by CEO tenure. Because we control for 
tenure in our estimation, it is the residual information that is being utilized for measurement of this power variable.

Panel A of Table I, reports the raw correlation coefficients between the three measures of CEO power. The correlations are all significant at $1 \%$ level but range only from -0.033 to 0.221 , suggesting that these measures are capturing different aspects of CEO power. Consequently, in tests that examine the effect of power on incentive pay, we will iteratively study each of the measures of power.

Panels B and C of Table I compare the summary statistics of key variables used in our analysis across measures of power and gives us an initial univariate look at the data. We report the mean values for firm characteristics associated with compensation - assets, volatility, returns on assets $(R O A)$ and return on stock (Rstock) - in Panel B. In Panel C, we report the means for total compensation, cash compensation, share ownership and tenure, across measures of power. In each panel, we present the overall mean values in the first column and then split the sample by low and high power. For PowerIndex we split the sample into terciles, while for other power measures split the sample based on their median values. Also note that since the three power measures are constructed from different data sources, the number of observations varies when we use each of these measures iteratively in our tests.

A few points from Panel B are worth noting. The mean $R O A$ is only $4.39 \%$, whereas the mean Rstock is over $16.5 \%$. Since the predictions are based on compensation equation that compares measures of performance drawn from similar distributions, in our empirical analysis we standardize these returns for comparability. While Insider\% and \% Appointed firms appear to categorize firms similarly along different dimensions, there appears to be more of a nonmonotonic relationship between Power Index and firm characteristics. High Insider\% and low \% Appointed firms are slightly smaller and have greater accounting returns. Classifying firms by Power Index reveals that medium power firms are larger and have greater accounting returns than low and high power firms. Firm volatility does not show any consistent pattern across these measures.

Panel C shows that \% Appointed CEOs receive more total and cash compensation than their low \% Appointed counterparts, while the relationship between PowerIndex and compensation is non-monotonic. Interestingly, total and cash compensation for high Insider\% CEOs is lower than their low Insider\% counterparts. This is not surprising, however, once we note that high Insider\% represent smaller firms and reinforces the need for a multivariate setting. For ShareOwned and Tenure the pattern is inconclusive across the measures of power. High Insider \% and \% Appointed CEOs also have larger shareholdings and longer tenures than their counterparts. These simple univariate splits provide only limited insight for how CEO power might impact compensation. We next turn to a more complete empirical model of compensation. 


\section{Empirical Strategy}

Prior studies identify a relation between power and compensation by regressing CEO compensation on measures of power and controlling for standard economic and ownership determinants of compensation (e.g., Core, Holthausen, and Larcker, 1999; Hallock, 1997). The specification often takes the form:

$$
\ln \left(W_{i t}\right)=\alpha_{0}+\alpha_{1} \text { Power }_{i t}+\alpha_{2} \text { ROA }_{i t}+\alpha_{3} \text { Rstock }_{i t}+X_{i t} \beta+\delta_{t}+\epsilon_{i t} .
$$

Indices $i$ and $t$ refer to firm and year. Compensation $W_{i t}$ is estimated in natural logarithms not only to help with the right skew of compensation, but also to be consistent with a model in which the returns to CEO effort are proportional to the size of the firm (Baker and Hall, 2004). $X_{i t}$ is the vector of human capital and ownership determinants of compensation described in the data section, while $R O A_{i t}$ and $R_{s t o c k}$ are accounting and stock performance measures respectively and $\delta_{t}$ denotes a series of year dummy variables.

Within our model specification we allow, for a level effect of Power on compensation, where Power denotes one of our three measures (done iteratively). Our objective is to identify rigging separately from what powerful CEOs receive in terms of higher average compensation. ${ }^{15} \mathrm{We}$ enrich model (6) along a few dimensions. First, we standardize $R O A_{i t}$ and $R s t o c k_{i t}$ by year and by 2-digit SIC code returns according to:

$$
\begin{aligned}
z R O A_{i t} & =\frac{R O A_{i t}-\overline{R O A}_{t}}{\sigma_{t}^{\text {ROA }}} \\
z \text { Rstock }_{i t} & =\frac{\text { Rstock }_{i t}-\overline{\text { Rstock }}_{t}}{\sigma_{t}^{\text {Rstock }}} .
\end{aligned}
$$

$\left\{\overline{R O A}_{t}, \overline{R s t o c k}_{t}\right\}$ and $\left\{\sigma_{t}^{R O A}, \sigma_{t}^{R s t o c k}\right\}$ are firm $i$ 's industry mean return and standard deviation respectively for accounting $(R O A)$ and stock (Rstock) performance. This standardization allows us to compare sensitivities across performance measures. ${ }^{16}$

Second, we alter equation (6) to capture rigging by introducing a $M_{a x}$ it term interacted with the power variable. $M a x_{i t}$ is defined as the ex post maximum return of the standardized performance measures $\left(z R O A_{i t}, z R s t o c k_{i t}\right)$ for firm $i$ in year $t$. The baseline specification after these modifications maps closely to the equation derived in Proposition 1 and is given by:

$$
\begin{aligned}
\ln \left(W_{i t}\right)=\begin{array}{l}
\alpha_{0}+\alpha_{1} \text { Power }_{i t}+\alpha_{2} z R O A_{i t}+\alpha_{3} z \text { Rstock }_{i t}+X_{i t} \beta \\
+\alpha_{4} \operatorname{Max}_{i t}\left\{z R O A_{i t}, z R \text { Rtock }_{i t}\right\} * \text { Power }_{i t}+\delta_{t}+\epsilon_{i t}
\end{array}
\end{aligned}
$$

The sensitivity of compensation to accounting and stock performance, $\alpha_{2}$ and $\alpha_{3}$, are inter-

\footnotetext{
${ }^{15}$ Grinstein and Hribar (2003) and Adams, Almeida and Ferreira (2005) have shown that CEO compensation is positively associated with the level of CEO power.

${ }^{16}$ We employ 2 digit SIC codes for this procedure. Using 3 digit SIC codes does not alter our results though we lose observations.
} 
preted as the pay-for-effort in each performance area relative to industry standardized returns. Since we take away the industry means from these performance measures and standardize them, the interpretation of these sensitivities is somewhat different from the sensitivity of compensation to raw accounting and stock performance in models like (6). Moreover, by industry adjusting we are examining effect on compensation after removing the type of luck factors that are central to the arguments in Bertrand and Mullainathan (2001) and Garvey and Milbourn (2006). Our main testable prediction is that the $\alpha_{4}$ coefficient on the $M a x_{i t}$ term interacted with Power $_{i t}$ will be positive.

Two concerns arise in such a specification. First, unobserved firm heterogeneity may affect both compensation and the explanatory variables, thereby biasing our results. Second, wages are sticky, and even though a large part of sticky wages may be compensation for management of assets and uncertainty (captured by the loadings on tenure, assets and volatility), the residual correlation requires attention.

We address the issue of unobserved firm heterogeneity residing in the error term by including firm fixed effects $\mu_{i}$ in the baseline specification. The fixed effects remove the time invariant firm characteristics which might bias our results. Note that the variation of rigging in incentives is not coming directly from the variation in power measures over time but instead is coming from the variation in $\operatorname{Max}\{z R O A, z R s t o c k\} *$ Power. As a result, rigging is identified even if there is no variation in power variables as long as there is sufficient within firm variation in $\operatorname{Max}\{z R O A, z R s t o c k\}$. The combination of including firm fixed effects and estimating with robust standard errors should be asymptotically sufficient to handle firm heterogeneity, even if within-firm errors are serially correlated. However, in a finite sample world, to ensure that our coefficients are estimated without bias, we implement (8) with one of the two following assumptions on the error term $\epsilon_{i t}$.

The first approach assumes that all of the serial correlation remaining in equation (8) is eliminated by including lagged performance measures in the baseline equation. In other words, we assume that:

$$
\begin{gathered}
\epsilon_{i t}=\beta_{1} z R O A_{i, t-1}+\beta_{2} z R s t o c k_{i, t-1}+\zeta_{i t} \\
\text { where } \zeta_{i t} \sim i i d .
\end{gathered}
$$

The intuition is that any serial correlation in compensation after conditioning on firm and CEO covariates is a reflection of an updating of managerial ability or a slowness in compensation reaction to performance or both. In such a setting, lagged performance is an important omitted variable, and its inclusion would be important for the unbiased estimation of rigging, especially since it is plausible that power may itself be a reflection of boards rewarding CEOs for past performance successes.

The second approach makes a different assumption on the error term; namely we assume that the error follows an AR process:

$$
\varepsilon_{i t}=\rho \varepsilon_{i, t-1}+v_{i t}
$$




$$
\text { where } v_{i t} \sim \text { iid. }
$$

The intuition is that beyond the effect of firm and CEO covariates and stationary firm effects, there are some unobserved factors affecting compensation at the firm level whose serial correlation is not zero and not equal to one. If $\rho=0$, then the estimation will produce a firm fixed effects solution. If $\rho=1$, then this approach converges to a first difference specification. ${ }^{17} \mathrm{In}$ the results section, we show that $\rho$ is significantly less than one and significantly greater than zero, suggesting that the most efficient estimating procedure should be an AR process with a firm fixed effect. The estimation using this second approach is a two-step process whereby we estimate the $\rho$ first by using initial error terms from the baseline equation (8) and then re-estimate the coefficients treating the $\rho$ as a constant in a GLS estimation.

\section{Empirical Results}

In all of the results below, we include side-by-side the estimates from the two approaches: lagged performance measures with firm fixed effects and robust standard errors and AR fixed effects estimation. The first subsection reports results excluding the rigging terms, so that we can examine whether the previously documented relation between power and compensation (Grinstein and Hribar, 2003; Adams, Almeida and Ferreira, 2005) is due, in part, to the omission of rigging in the empirical specification. The following subsections then cover our main rigging results, results with expanded performance measures, estimates concerning the potential for more rigging in firms with high human capital and uncertainty, and finally tests for whether stronger governance along other dimensions attenuates rigging effects.

\section{VI.A Level Effect of CEO Power without Rigging Variables}

The standard estimation of compensation on power measures, performance, other economic and ownership determinants of compensation and year dummies is presented in Table II. In particular, the log of total dollar compensation is regressed on one of our three power measures (done iteratively), zROA, zRstock, firm size, volatility, CEO tenure and its square, CEO ownership percentage and its square, and the valuation of exercisable options held by the CEO. In Columns (1), (3) and (5) the estimation is fit with lagged performance measures with firm fixed effects. Columns (2), (4) and (6) replaces the specification with the AR fixed effects specification.

The estimations in Table II show that compensation is positively and significantly associated with two of the three power variables - PowerIndex and Insider \% - in both the lagged performance fixed effect and AR fixed effects specifications. The magnitude of the coefficient

\footnotetext{
${ }^{17}$ In previous versions of the paper, we have shown that all of our results hold when we implement a standard first difference specification as well.
} 
estimate on these measures is similar in both the specifications. For instance, the estimate on PowerIndex is about 0.057 in both Columns (1) and (2).

The coefficient estimates on the other variables are as expected. The contemporaneous standardized performance measures, $z R O A$ and $z R s t o c k$, are positively associated with compensation in all the estimations. ${ }^{18}$ In addition, the lagged performance measures are also positive and significant in all the specifications where they are included, suggesting updating of managerial ability or a slowness in compensation reaction to performance or both.

The elasticity of compensation with respect to assets ranges narrowly from 0.32 to 0.36 , across columns with little difference between the lagged performance fixed effects and the AR fixed effects specifications. Volatility is also positively associated with compensation, as the prior literature finds, but its significance is not robust across columns due to inclusion of firm fixed effects. When we estimate the model with firm random effects instead, we find that compensation elasticity to assets remains materially the same, and the coefficient on volatility becomes much larger and significant, in line with the theory of Murphy and Zabojnik (2005) and the empirical work of Eaton and Rosen (1983). Consistent with Adams, Almeida and Ferreira (2005), we find that the value of CEOs' past option holdings are positively associated with CEO compensation. Share ownership coefficients suggest an inverted-U relation with compensation consistent with performance regressions of Himmelberg, Hubbard and Palia (1999). Finally, the association between tenure and compensation depends on which power measure is included in the model. In general, it has no significant effect on compensation once all of the controls are included.

It is important to observe that the impact of power on CEO compensation is economically meaningful - in addition to being statistically significant. Using the coefficients from Column (1) of Table II, for instance, we observe that a within-firm one standard deviation increase in the PowerIndex (0.75), keeping other variables at their sample means, raises compensation by about $\$ 200,000$ or $4.5 \%$. The effects are qualitatively as large for a standard deviation increase $\%$ Insider as well.

\section{VI.B Main Results: Rigging Effect of CEO Power}

Panel A of Table III presents the main findings of our study with side-by-side estimates from the two approaches. The economic and ownership determinants of compensation - firm size, volatility, CEO tenure and its square, CEO ownership percentage and its square, and the valuation of exercisable options held by the CEO - are included in the estimation but since there is little change from the coefficients presented in Table II, they are omitted in this table and subsequent tables for brevity. Columns (1) and (2) add Max on to the basic specification

\footnotetext{
${ }^{18}$ There has been an on going debate on whether incentive sensitivities are themselves low or high. The debate was started by Jensen and Murphy (1990) who argued that the incentive payments to CEOs seemed low. This has been argued against by researchers who argue that these incentives are consistent with reasonable levels of managerial risk aversion (see Tirole, 2006).
} 
from Table II and show that the coefficient estimate on this term is significant. This suggests that our first prediction is borne out for a CEO with average power in the sample. Estimates on performance measures and other firm and CEO characteristics also maintain their signs and significance.

Columns (3) to (8) assess whether the significance of Max in the first two columns varies with CEO power, as predicted by our model. We directly follow the specification implied by Proposition 1 in including interaction of Max with CEO power variables in the estimation. ${ }^{19}$ As in Table II, Columns (3) to (8) add power measures iteratively. In all the specifications, power variables enter as a level variable and as an interaction with Max. Indeed, we find that consistent with our main prediction, the interaction of Max with CEO power variables is positively significant (i.e., $\alpha_{4}>0$ ) for all the three power measures. Specifically, the coefficient estimate on the interaction of all the power variables with Max is positively significant, at least at $5 \%$ confidence level, in all of the specifications. Additionally, the level effect of the power measures (i.e., not interacted with $M a x$ ) is similar, in most cases, to the estimates in Table II.

A few points are worth noting regarding the coefficients on the standardized performance measures themselves. The coefficients on $z R O A$ and zRstock in Columns (1) and (2) of Table III remain positively significant as our theory would suggest but are a little more than half the magnitude of those in Table II. This is true across Columns (3) to (8) in Table III. In general, the coefficients on standardized measures are smaller in magnitude than coefficients on the performance measures found elsewhere in the literature (e.g., Core et al. (2003)), but a direct magnitude comparison is not appropriate for a few reasons.

First, standardizing our measures by taking out industry means removes a large part of pay-for-performance sensitivity due to luck (e.g., Bertrand and Mullainathan, 2001). In addition, part of what the previous literature has found to be incentive pay is really rigged incentive pay, and as a consequence, we do expect the magnitude of sensitivities on these performance measures to fall. Finally, the lagged performance measures remain large and positively significant in all but one of the specifications, suggesting a slowness in compensation reaction to performance. We believe that a combination of these reasons explains why our current period performance sensitivities are smaller in magnitude than previous work. What we want to emphasize is that the inclusion of the rigging term lowers the industry adjusted pay-for-performance sensitivity in an economically meaningful way.

The evidence presented in Table III is consistent with our first prediction - that powerful CEOs' compensation is positively sensitive to the better performing measure of firm performance. An interesting finding is that rigging seems to be driven both by the personal power measure of CEO influence (high PowerIndex) and board weakness (high Insider\% and high \%

\footnotetext{
${ }^{19}$ As indicated in Section VI.C, our results hold if we add Max term in addition to the interaction of Max with CEO power variables. The coefficient on Max (as reported in Columns (1) and (2)) becomes insignificant and the significance is instead captured by Max interacted with power variables. We follow the specification only including Max interacted with power variables since that is the structural wage equation implied by our model.
} 
Appointed). The inference from these results is that powerful CEOs are better positioned to manipulate the incentive portion of their compensation when they face a board that is weak by design. The evidence suggests, therefore, that policies that strengthen boards, such as by increasing independent members, may reduce the rigging of incentive pay.

How important are these rigging findings? For our purposes the most salient economic issue is how much (in dollars and in percent) of pay-for-performance is rigged rather than a result of incentives. We can write the expected compensation $E(W)$ from our semi-log specification of compensation as:

$$
E(W)=\exp \left\{\alpha_{0}+\alpha_{1} \text { Power }_{i t}+\alpha_{2} z R O A_{i t}+\alpha_{3} z \text { Rstock }_{i t}+\alpha_{4} \text { Max } i t * \text { Power }+X_{i t} \beta+\frac{1}{2} \sigma_{\epsilon}^{2}\right\} .
$$

For now, we assume that $z R O A$ and $z$ Rstock are independent and appear as the Max with probability equal to a half. Noting that a one unit change is one standard deviation, and focusing on Insider\% from Column (6), we calculate the comparative static for the overall incentive pay effects (from the mean values) as:

$$
\begin{aligned}
\frac{d E(W)}{d z R O A} & =E(W) *\left(\alpha_{2}+\alpha_{4} * \frac{1}{2} * \text { Insider } \%\right)=\$ 509,000 \\
\frac{d E(W)}{d z \text { Rstock }} & =E(W) *\left(\alpha_{3}+\alpha_{4} * \frac{1}{2} * \text { Insider } \%\right)=\$ 212,000 .
\end{aligned}
$$

The rigged dollar portion of this for both performance measures is equal to $E(W) * \frac{1}{2} \alpha_{4} *$ Insider $\%)=\$ 81,500$. In other words, $16 \%$ of incentive pay for $z R O A$ and $38 \%$ for $z$ Rstock are due to rigging. Similar calculations using the other power measures result in marginally higher magnitudes. We may be overestimating the effect of rigging by using a 1 unit change. The within-firm sample standard deviations for $z R O A$ and $z$ Rstock are 0.54 and 0.78 respectively. Using these numbers instead suggests that rigging explains $8 \%$ of compensation sensitivity to $z R O A$ and $29 \%$ of the sensitivity of compensation to $z R$ stock.

One can argue, quite correctly, that the Max term potentially jumps back and forth between the performance variables, and it is therefore inappropriate to use a (continuous) comparative static assessment of impact with the performance measures assumed to be independent. To account for the correlation between performance measures, we conduct a more sophisticated economic magnitude calculation following Manning (1998) using the data to determine which measure is better ex post, observation by observation. The magnitude of our results remains qualitatively similar to those from the simpler calculations above.

There are two aspects to the economic significance calculations that we want to highlight. These calculations account for the correlation between $z R O A$ and $z R s t o c k$ and the fact that, besides gaining in good states, rigging results in CEOs suffering less in bad states of the world. To see these aspects in detail we analyze how the incentive pieces of compensation react when comparing mean performing firms on both measures to those that perform high or low on one of the two standardized measures. Since the correlation between $z R O A$ and $z$ Rstock in the whole sample is 0.20 , we assume that a 0.2 unit change in $z$ Rstock accompanies a 1 unit change 
either up or down in $z R O A$, and vice versa. In addition, because rigging only pays off when one measure performs better than the other, we need a distribution of what the difference of the performances look like. To accomplish this, we categorize firms into high $(H)$, medium $(M)$, and low $(L)$ tertiles of their predicted compensation. We then calculate the improvement in CEO compensation implied by the estimated coefficients from Table III for moving from a middle performance in both measures (i.e., $z R O A_{M}$ and $z$ Rstock $k_{M}$ ) to high or low performance in either $z R O A$ or $z$ Rstock.

Table IV reports the results from this analysis for Insider\%, which is representative (and conservative) of the results using other power measures. Averaging over the up movements (higher $z R O A$ and higher $z$ Rstock) suggests that slightly over $33 \%$ of the sensitivity to performance implied by our coefficients comes from rigging. In addition, for down movements, about $10 \%$ of the sensitivity of compensation to down movements is from rigging. These calculations underscore that besides allowing CEOs to gain in good states, rigging also buffers pay-for-performance declines after poor performance.

Finally, since we standardize our performance measures by removing contemporaneous industry shocks, we are likely to lose situations of rigging where ex post manipulation of performance variables is driven by industry shocks. In that sense our estimates provide a lower bound on the amount of rigging. In order to estimate what the upper bound of rigging is likely to be, we reconstruct our performance measures by allowing them to pick up the effects of contemporaneous industry shocks. Since the distribution of raw accounting and stock return realizations during the sample period are quite different, it is difficult to directly compare the two raw measures in order to get a sensible measure of ex post maximum return performance $\operatorname{Max}\left\{R O A_{i t}\right.$, Rstock $\left.k_{i t}\right\} .^{20}$ To make the distributions of the two returns comparable so that $\operatorname{Max}\{.,$.$\} can be sensibly computed, we still adjust accounting and stock returns by$ standardizing them. However, instead of computing and standardizing by the industry mean and standard deviation of the return every year, we now standardize by industry means and standard deviation of the return computed over the entire sample period. By doing so, we allow the impact of contemporaneous industry shocks to potentially show up in the rigging estimates.

We then re-estimate the specification used in Table III, employing these measures instead of the ones used in Table III. For brevity, the results are presented in Table A.I of Web Appendix. As can be observed, we find that consistent with our main prediction, the interaction of Max with CEO power variables is positively significant for all the three power measures. Not surprisingly, these estimates are larger than those obtained when we remove the impact of contemporaneous industry shocks. For instance, we find that $28 \%$ of incentive pay for $z R O A$ (vs. $16 \%$ ) and $61 \%$ for $z$ Rstock (vs. 38\%) are due to rigging when \% Insider is employed as a power measure. Using other power measures for calculations suggests that the upper bound on rigging estimates might be of the order of $20 \%$ to $28 \%$ for the accounting return measure and

\footnotetext{
${ }^{20}$ For instance, the mean accounting return is $4.4 \%$ (standard deviation of $6 \%$ ) while the mean stock return is $16.5 \%$ (standard deviation of $38 \%$ ).
} 
$30 \%$ to $60 \%$ for the stock return measure. Alternatively, using within-firm sample standard deviations for accounting and stock returns instead of unit changes, we get the upper bound on rigging to be of the order of $16 \%$ to $22 \%$ for accounting return and $28 \%$ to $57 \%$ of stock returns.

We investigate the effects of standardizing performance on our rigging estimates in another way as well. We follow the approach discussed above, but instead of standardizing by industry means and standard deviation of the return computed over the entire sample period, we now standardize by sample means computed over the entire sample period. The idea behind this is to remove effects of industry all together from the rigging estimates. As can be seen from estimates in Table A.II of Web Appendix, the effect of rigging is even larger. In particular, using this approach, the upper bound on rigging estimates is of the order of $26 \%$ to $43 \%$ for the accounting return measure and $38 \%$ to $65 \%$ for the stock return measure.

\section{VI.C Robustness of the Rigging Effect}

We conduct additional tests to confirm that our results are robust. First, there could be a concern that all forms of compensation may not be fully fungible and that we should apply the model to elements of compensation that are explicitly tied to both performance measures (e.g., restricted stock and stock option grants may potentially not be tied explicitly to accounting returns). ${ }^{21}$ Note that so far we have included both the salary as well as equity grants to assess the impact of CEO power on compensation. We are persuaded on this choice by Bebchuk, Fried and Walker (2002) who argue that rent-seeking executives may seek to increase their pay through option grants rather than cash in an attempt to camouflage pay to mitigate external scrutiny and criticism. In particular, it may be easier for boards to justify giving CEOs stock and option grants to provide incentives, rather than to give outright bonus awards to avoid outrage of outsiders. Nevertheless, to alleviate the concern that rigging is picking up some spurious effects due to inclusion of equity grants, we consider the main rigging specification with only the log of CEO's cash compensation as the dependent variable.

The regression results in Table $\mathrm{V}$ show that our results are qualitatively similar to those reported in Table III. Consistent with our theory we find that the coefficients on $z R O A$ and $z R$ stock are positively significant. More importantly, the rigging effect for each of the power variables is positive and significant in both specifications for two out of three power measures. The magnitude of the rigging coefficient is however a little more than half the magnitude of those in Table III. For example, the rigging effect using Insider\% with cash compensation (0.08) is about half of that reported in Table III (0.18). This is not surprising since by removing stock grants from the salary we have taken away the component that has accounted for much of the increase in the compensation of CEOs in the 1990s (Hall and Murphy, 2003).

\footnotetext{
${ }^{21}$ In unreported tests, we also confirm that stock grants are sensitive to both $z R O A$ and $z R s t o c k$ in our sample. Moreover, the results also suggest that our rigging results are largely borne out even when we take only option grants or restricted stock grants as the compensation variable.
} 
Second, there may be a concern that our results could be sensitive to our choice of performance measures. To alleviate this concern we construct another performance measure (operating earning per share, $O E$ ) that has been used in the compensation literature following Murphy (1999). We calculate this as a firm's net income in a given year (after preferred stock dividends but before common stock dividends) divided by total equity (excluding preferred shares). We then standardize this measure using the same procedure as (7) and construct $z O E$. We define $\operatorname{Max}_{i t}^{3}$ as the maximum ex post return for the standardized performance measures $z R O A_{i t}, z R s t o c k_{i t}$ and $z O E_{i t}$ for a firm $i$ in year $t$. Using this, we re-estimate regressions in Table III and present the results in Table VI. As is reported in Columns (3) to (8), consistent with our main prediction, the interaction of $\mathrm{Max}^{3}$ with CEO power variables is positively significant (i.e., $\alpha_{4}>0$ ) for each of the three power measures.

Third, we examine how our rigging estimates vary over years in our sample. This allows us to assess whether rigging is being driven by a particular time period (for instance the tech-bubble period). To do so, in unreported tests, we enhance our main specification (8) by including an interaction of the rigging variable with year dummies (i.e., Max $x_{i t} * \operatorname{Power}_{i t} * \delta_{t}$ ). We find that the estimates are largely robust across the sample period.

A related concern is that the rigging results could be driven by a greater sensitivity of CEO pay to zRstock when the stock does well. Garvey and Milbourn (2006), for instance, show that CEOs are more likely to be rewarded when the stock does well. Rajgopal, Shevlin and Zamora (2006) also confirm that CEO's pay is shielded from market downturns. Thus, it could be argued that the Max term is capturing greater sensitivity of compensation to performance in high stock performance periods, reflecting generous rewards given when boards and shareholders are happy. However, such an argument would not explain why the sensitivity was increasing in CEO power. In any event, this possibility can be easily tested. A similar argument could be made with respect to greater compensation sensitivity to accounting returns when these returns are high. To test these concerns, we remove the observations with returns in the top quartile of each performance measure for that year and re-estimate our regressions. Our results (unreported) suggest that the Max term interacted with power measures remains positive and significant when high accounting and stock return observations are removed. The results imply that rigging is not simply an artifact of greater sensitivity of pay in high performance periods.

Next, we ensure that our results are not driven by difficulties in controlling for nonlinearities in the CEO's compensation contract. Again, it is unlikely that this could be driving our results since it is unclear why the non-linearity in performance payoff would induce systematic variation of $\mathrm{CEO}$ compensation related to power variables. Nevertheless, we repeat all our tests controlling for squares and cubes of the performance measures. In each case, our results are qualitatively similar. We also allow the power variable to interact with $z R O A$ and $z R$ stock, not just the Max variable. We find that our coefficients of interest remain robustly significant after inclusion of these variables. We also explored the possibility that our effects are driven in part by CEO incentive contracts providing insurance i.e., the incentive contracts that 
CEOs get are option like. To alleviate this concern, we controlled for $\operatorname{Max}\{z R O A, z R s t o c k\}$, $\operatorname{Max}\{z R O A, 0\}$ and $\operatorname{Max}\{z R s t o c k, 0\}$ in our analysis and find that our results are not affected by the inclusion of these variables. ${ }^{22}$

Finally, we re-estimate these regressions replacing firm fixed effects with CEO fixed effects. To have sufficient in-firm variation such that the CEO fixed effects do not eliminate our ability to identify power, we restrict the sample to firms with more than two CEOs over the period. Although the sample becomes much smaller, we find results that are qualitatively similar to the ones reported.

Our main rigging results from Section VI.B and Section VI.C can be summarized as follows: powerful CEOs facing weak boards have greater sensitivity to the more favorable performance measure in a given period. With our coefficients, rigging explains about $10 \%-30 \%$ of the compensation sensitivity to performance. Powerful CEOs receive both a higher level of pay as well as returns from rigging.

\section{VI.D Variation in Rigging with R\&D Intensity and Industry Volatility}

In this section, we investigate the cross-sectional variation in rigging of incentive pay. Our second prediction suggests that the rigged portion of incentive pay should be increasing in: (i) the human capital intensity of the CEO and (ii) the uncertainty about the firm's future prospects. To test this prediction, we sort our data into quartiles based on R\&D to sales ratio and industry volatility and examine if rigging is stronger among firms in the highest quartile of each of these measures. We use sorts rather than interactions in this section and the next not just for ease of exposition but also because our tests involve multiple interactions which may lead to collinearity driven results.

Table VII presents the results from both the lagged performance firm fixed effects and the AR firm fixed effects specifications. In the first two columns, we break the sample into the lower three quartiles and in the third and fourth column into the upper quartile in terms of R\&D intensity. The results in Columns (1)-(4) strongly support our prediction that the rigged component of the pay is substantially larger in magnitude for CEOs with greater human capital intensity. In particular, the coefficient estimate on Max interacted with power variables is statistically significant in only the top most quartile of R\&D intensity in all the specifications. Moreover, the rigged component of pay is substantially larger in magnitude for CEOs in firms

\footnotetext{
${ }^{22}$ We also explored the possibility that our results might be driven by complexity of the job. The notion is that different facets of CEO job are only important in complex firms and therefore both the measures are important only when the complexity of the job is high. We followed Murphy and Zabojnik (2005) and Eaton and Rosen (1983) and proxied for the complexity of the job using asset size. To test the conjecture, we then divided the firms into quartiles based on their asset size and examined if the sensitivity of CEO pay to the two performance measures was confined only to large firms. We do not find this to be the case. The sensitivity of CEO pay to both the measures is statistically significant across size quartiles. We obtain similar results when we form quartiles based other alternative measures of complexity like number of segments, R\&D intensity and volatility.
} 
with higher human capital intensity. For instance, using Insider\% as the power variable the coefficient estimate from the fixed effect specification suggests that incentive pay is rigged about $60 \%$ more by CEOs in firms that lie in the top quartile of firms sorted by R\&D intensity.

Columns (5) to (8) similarly splits the sample to the lower three and upper most quartile of firms according to industry volatility. As predicted, we largely find that the rigged component of pay is only significant for CEOs when the uncertainty about the firm's future prospects is higher. For robustness, we proxy for CEO's human capital by the number of employees to sales ratio of the firm, number of business segments of the firm and diversification index of the firm and measure the uncertainty regarding the firm's prospects using dispersion of analyst forecasts. Our results (unreported) using these alternative measures are qualitatively similar to those reported in Table VII.

To summarize, our results in this section are consistent with our second prediction. We find that powerful CEOs rig their incentive pay more when their human capital intensity is higher and when the uncertainty about the firm's future prospects is greater.

\section{VI.E Impact of Governance on Rigging}

This section examines whether rigging in firms with weak board governance is moderated by relatively high governance standards along other dimensions. As discussed in the hypothesis section, it may be more difficult for compromised boards to engage in rigging when other areas of governance are stronger. Prior findings in the literature suggest that stronger governance may restrain compensation: Santerre and Neun (1986) find, for instance, that compensation is negatively related to the concentration of shareholders, and Almazan, Hartzell and Starks (2005) report that pay-for-performance sensitivity is higher with the level of active institutional shareholdings.

We follow the approach in Section VI.D and analyze the impact of governance by dividing firms into groups based on governance and re-estimating our main regression equations in each group. Our expectation is that the results on rigging should be weaker among firms with strong governance along other dimensions. The results, presented in Table VIII, strongly support this notion. The first four columns document this result for the lagged performance fixed effects and AR fixed effects specifications using a split of the sample by IRRC/ Gompers et al. (2003) Index while the next four columns presents results with these specifications using a split according to institutional holdings.

The rigging coefficient is largely consistently positive and significant for firms in the lower three quartiles of governance as indicated in Columns (1), (2), (5) and (6). In addition, as can be observed from Columns (3), (4), (7) and (8), the rigging coefficient becomes insignificant for the quartile of firms with the largest institutional holdings and the highest governance score on the Gompers et al. (2003) governance index. The rigged component of pay is substantially larger in magnitude for CEOs in firms with weaker governance along other dimensions. 
Overall, the results in this section indicate that rigging is less evident in firms with powerful CEOs when governance in stronger. ${ }^{23}$ While these results should be interpreted cautiously, they raise the possibility that stronger governance along other dimensions may blunt CEO power.

\section{Rigging and Value}

In this section, we test our final prediction by examining how the rigged portion of incentive pay is related to firm value creation. Aligning a CEO's goals to those of shareholders through incentive contracts should create future value for the firm (Holmstrom, 1979). This is not true, however, for the portion of the incentive contract that may be rigged, rather than true incentive compensation. Our third prediction is that the rigged portion of incentive pay destroys firm value. An alternative explanation consistent with our results thus far is that boards rationally change the weights on performance measures in the CEO contract as an optimal incentive device. In this alternative, shifting of performance weights could contribute positively to firm value. ${ }^{24}$ Thus, by examining the relationship between the rigged portion of incentive pay and future firm performance, we can distinguish between these alternatives.

To establish a relationship between firm value and incentives, we follow an approach similar to Core et al. (1999). In a two-step estimation, they show that the incentive part of pay explained by various economic and governance variables has a significant impact on firm value. Our method is likewise a two-step procedure. First, we estimate how much variation in the incentive part of pay can be explained by power measures, over and above the variation explained by economic and governance variables. Second, we examine the relationship between the firm's future performance and the incentive pay that is explained by the power variables.

More formally, in the first step, we estimate the compensation equation using the lagged performance fixed effects specification given in (9) or AR with fixed effects using equation (10), from which we take two sets of predicted values:

$$
\begin{array}{r}
\text { IncentivePay } \text { Pat }_{i t}=\widehat{\alpha}_{2} z R O A_{i t}+\widehat{\alpha}_{3} z \text { Rstock }_{i t} \\
\text { RiggedIncentivePay }_{i t}=\widehat{\alpha}_{4} \text { Max }_{i t}\left\{z R O A_{i t}, z \text { stock }_{i t}\right\} \text { Power }_{i t} \\
\text { PowerIncentivePay }_{i t}=\widehat{\alpha}_{1} \text { Power }_{i t}
\end{array}
$$

\footnotetext{
${ }^{23}$ This notion is broadly consistent with Kim and $\mathrm{Lu}$ (2009) who find a hump shaped relation between firm's $\mathrm{Q}$ and CEO share ownership only when governance is weak. They interpret this as manifestation of some CEOs capturing incentive contracts under weak external governance. See also Agrawal and Nasser (2009) for similar evidence.

${ }^{24}$ Under this alternative one could argue that firms tend to use ex post settling up in environments where there is a high degree of uncertainty - with insider dominated boards (and other indicators of CEO power), serving to reassure the CEO that there would not be ex post expropriation. The key difference between rigging and the alternative explanation is that, unlike with rigging, the shifting of weights to favor CEOs should not be destructive of firm value. We thank the referee for suggesting this alternative.
} 
Incentive Pay $_{i t}$ is the portion of CEO compensation explained by the sensitivity to performance measures. Rigged $\widehat{\text { IncentivePay }}$ it is the portion of CEO compensation explained by the sensitivity to the best performing measure interacted with Power, while Power IncentivePay is the portion of CEO compensation explained by the level of power variables. We get two sets of predicted values, one from the lagged performance fixed effects specification and one from the AR fixed effects specification. Because the estimation equation controls for variables $X$ known to be associated with compensation and for firm heterogeneity through firm fixed effects, the predicted incentive pay variable should be comparable across firms. ${ }^{25}$

The second step of the analysis is to examine the relationship between the firm's future performance and the rigged incentive contract variables. We estimate the following model:

$\begin{aligned} y_{i, t+2}= & \gamma_{0}+\gamma_{1} \text { Incentive Pay }_{i t}+\gamma_{2} \text { Rigged } \widehat{\text { IncentivePay }}+\gamma_{i t} \text { Power } \widehat{\text { IncentivePay }}{ }_{i t} \\ & +Z_{i t} \lambda+\mu_{i}+\delta_{t}+\varepsilon_{i, t+2} .\end{aligned}$

$y_{i, t+2}$ is a measure of future firm performance $(Q, R O A$ or four factor $\alpha)$ two years ahead. To obtain $\alpha$, for each firm, we estimate the time-series regression of the excess stock returns on four zero-investment factor portfolios excess market return, size, value, and momentum using the 36 months of data subsequent to the year we want to estimate $\alpha$ for. Alpha is then measured as a sum of an intercept of the model and the residual, as in Carhart (1997). $Z_{i t}$ are variables known to explain future performance following Core et al. (1999) and Himmelberg et al. (1999). These include firm size, firm volatility, CEO holdings of stock and stock options and past annual sales growth of the firm. Firm and year fixed effects are included to remove unobserved firm and time heterogeneities which might be correlated with the performance variables of interest. Finally, the standard errors in the second stage are bootstrapped (by at least 250 replications or more) to reflect the error in generated regressors. Based on prior evidence in Core et al. (1999), we expect a positive relation between firm value and incentives (i.e., $\gamma_{1}>0$ ). In addition, our theory predicts a negative relation between firm value and rigged incentives (i.e., $\gamma_{2} \leq 0$ ).

Table IX presents the second-stage tests (equation (15)). The dependent variable is measured by two year ahead $Q \mathrm{~s}$ in Columns (1) and (2), two year ahead $R O A \mathrm{~s}$ in Columns (3) and (4) and two year ahead four factor $\alpha$ in Columns (5) and (6). The first column uses the fixed effects specification in the first stage, while the second column uses the AR fixed effects specification. $Q$ is the market to book ratio and is measured by the market value of equity of the firm divided by the book value of equity. Four factor $\alpha$ is constructed using monthly observations

\footnotetext{
${ }^{25}$ In unreported tests, we create a second set of incentive decompositions to be consistent with Mehran (1995). Rather than predicting the incentive pay amount rigged and not rigged for each firm, we predict the incentive pay percentage rigged and not rigged for each firm by estimating:

$$
\frac{\text { EquityPayit }_{\text {TotalCompensation }} \text { it }}{\text { Tolit }^{\text {economic }}} \eta_{2}+X_{i t}^{\text {governance }} \eta_{3}+\eta_{1} \text { Power }_{i t},
$$

and then take predicted values as in the main tests. The dependent variable in this case is the percentage of compensation that is equity based. The results using this alternative specification are qualitatively similar.
} 
of next 36 months, with the monthly factors obtained from Ken French's website. ${ }^{26}$

The results support the hypothesis that the part of the incentive pay that is rigged has a negative impact on subsequent firm performance. Rigged Incentive Pay - both in the fixed effects and AR fixed effect specifications - is negative and significant across all columns. We also find that, as in previous studies, the economic and governance components of the incentive pay have a positive impact on firm value, while level of power by itself has a negative impact on subsequent firm performance. Since the effect of Rigged Incentive Pay is of offsetting sign to Incentive Pay, these results imply that in order to isolate the full effect of real, non-rigged incentives, it may be important to remove portions of incentive pay that do not result from economic and governance fundamentals.

Our estimates are economically as well as statistically significant. Estimates from Column (1) suggest that a within firm one standard deviation more in rigged incentive pay (0.046) induces a percentage change of $4.8 \%$ from the mean Q of $2.3\left(4.8 \%=\frac{\{2.41 * 0.046\}}{2.3}\right)$. If the book level of assets remain the same over the period, this is a market valuation drop of about $\$$ 80 million for the median firm in our sample. Likewise, return calculations are economically meaningful. Using the results in Column (4), a within firm one standard deviation increase in rigged incentive pay decreases yearly ROA by $0.36 \%(=8.04 * 0.046)$, a percentage change of more than $7.5 \%$ over the mean ROA of $4.8 \%$. Similarly, the estimates in Column (5) suggest that a within firm one standard deviation increase in rigged pay results in $0.0007\left(=0.015^{*} .046\right)$ less monthly alpha, or about $0.82 \%$ less risk adjusted return per year.

To summarize, consistent with our prediction, we find that the rigged part of incentive pay has a significant negative association with subsequent $Q$, operating return on assets and risk adjusted returns. Prior research (e.g., Jensen and Murphy, 1990) suggests that most firms could increase value by using more equity-based compensation. Our analysis, however, shows that the incentive structures are also vulnerable to rigging by powerful CEOs in the face of weak boards. Contract rigging is not simply a transfer of value to the CEO; it is associated with negative future performance. Our main conclusion from the value analysis in this section speaks to the agency-substitution versus rent skimming debate concerning the use of incentive contracts for powerful CEOs. Our results strongly indicate that incentive pay used to counter powerful CEO's lack of monitoring is weakened by incentive contract rigging.

A few caveats are in order. First, since our results suggests that rigging is associated with poor governance, some of the value loss could remain even if actions could be taken to entirely eliminate rigging (for example by requiring fixed weights on performance and fully disclosed contracts). In addition, while our analysis documents value loss associated with rigging of incentives by powerful CEOs, it cannot precisely nail down which actions by CEOs lead to this

\footnotetext{
${ }^{26}$ The coefficients on other variables are consistent with those reported in previous literature. For instance, consistent with the findings in Himmelberg, Hubbard and Palia (1999), we find that CEO's holdings of stock don't directly matter in a model with firm fixed effects, while it is significant in a model without firm fixed effects. Stock options on the other hand are positive and significantly associated with firm value in all the specifications.
} 
value loss.

Finally, note that we are not making any economy wide welfare statements. Though one can arguably come up with the loss of rigging by considering the set of firms where rigging might be expected to be particularly severe, this value loss will not be equivalent to welfare loss to the economy. For instance, weak governance and rigging may cause a firm to become less productive - but some of its loss in profitability may well be reflected in higher growth and profits of its competitors. Hence, the social cost may be substantially less than the value loss to a specific set of firms.

\section{Conclusion}

We hypothesize that powerful CEOs rig the incentive part of their pay. Specifically, we use the term rigging to mean that the CEOs slant the weights on the performance measures towards the better performing measures. We formalize the intuition in a simple model in which powerful CEOs are able to extract rents by opportunistically altering the focus of their incentive pay. Our model delivers several testable implications: (1) We expect rigging to be increasing in CEO power. (2) We also expect rigging by the CEOs to be greater when the human capital intensity of the CEO and uncertainty about the firm's prospects are high. (3) Finally, we expect firm performance to be decreasing in the amount of rigging.

Using a large panel of U.S. firms from 1992-2003, we find support for all our predictions. We find that rigging explains between $10 \%$ to $30 \%$ of the incentive pay sensitivity to performance. We also show that rigging may explain some of the lack of sensitivity to negative performance. Tests for the cross-sectional importance of rigging reveal that rigging increases with CEO human capital and with the uncertainty of a firm's prospects. Stronger governance along other dimensions moderates contract rigging by powerful CEOs. Rigging of incentive pay is shown to be associated with a decrease in future firm performance and value.

Our analysis raises doubts about whether observed equity based compensation fully serves as an incentive mechanism. The findings are of particular importance in the agency-substitution versus rent skimming debate: if setting high incentive contracts for powerful CEOs in firms is rendered ineffective by rigging, then the agency problem inherent in separation of ownership and control may be more severe than previously realized. Overall our evidence is more consistent with powerful CEOs skimming rents in the form of camouflaged incentive pay.

An issue we do not directly address in the paper is why shareholders appear to stick with powerful CEOs who leak firm value over time. We suspect that there are at least two reasons: The first reason is that, by its nature, rigging is hard to detect. Much like the recent backdating literature, while our empirical results show that the rigging coefficient is very statistically significant, this only implies that firms with powerful CEOs are, on average, engaging in this behavior. It would be difficult to pin down precisely which CEOs are actually 
doing this. In addition, and as we discussed in connection with the model, with some CEOs and boards having every incentive to camouflage excessive compensation, shareholders will tend to learn only gradually about the existence and scale of rigging that might be present in the firm. A second reason is that there are significant frictions (e.g., related to CEO labor market; see Hadlock and Fee, 2003), for instance the cost of launching a proxy fight, that can discourage collective action from shareholders towards replacing powerful CEOs.

The findings have important policy implications. A direct solution to rigging would be to require explicit disclosure of ex ante incentive pay contracts. It is, therefore, reassuring to note regulatory efforts in this regard, with the SEC sending letters to 350 companies in 2007 critiquing the way they described the pay of their top executives. ${ }^{27}$ In the absence of better disclosure, the good news from our paper is that contract rigging might be reduced in other ways as well. Our results suggest that policies that increase the independence of boards may be effective in reducing contract rigging by powerful CEOs. In addition, rigging may be moderated in firms with stronger governance along other dimensions.

\footnotetext{
${ }^{27}$ As one might expect, this effort at increasing disclosure has encountered resistance from several firms. For instance, in response to the letters from SEC, Baxter International's corporate secretary and associate general counsel, wrote that there were limits on what he was willing to tell the SEC, in order to avoid disclosing confidential information. He also indicated that such revelations would not provide "substantial value to investors in understanding our compensation policies and decisions." (WSJ, January 29, 2008)
} 


\section{References}

1. Acharya, Viral, Kose John and Rangarajan K. Sundaram, (2000), "On the Optimality of Resetting Executive Stock Options", Journal of Financial Economics, 57:1.

2. Adams, Renee, Heitor Almeida, and Daniel Ferreira, (2005), "Powerful CEOs and their Impact on Corporate Performance", Review of Financial Studies, 18:4.

3. Almazan, Andres, Jay Hartzell and Laura Starks, (2005), "Active Institutional Shareholders and Costs of Monitoring: Evidence from Executive Compensation", Financial Management, 34:4.

4. Anup, Agrawal and Tareque Nasser, (2009, "Blockholders on Boards and CEO Compensation, Turnover and Firm Valuation", Working Paper.

5. Baker, George P. and Brian J. Hall, (2004), "CEO Incentives and Firm Size", Journal of Labor Economics, 22:1.

6. Banker, Rajiv J. and Srikant M. Datar, (1989), "Sensitivity, Precision and Linear Aggregation of Signals for Performance Evaluation", Journal of Accounting Research, 27:1.

7. Bebchuk, Lucian, Jesse Fried and David Walker, (2002), "Managerial Power and Rent Extraction in the Design of Executive Compensation", University of Chicago Law Review, $69: 3$.

8. Bebchuk, Lucian and Jesse Fried, (2004), "Pay without Performance: The Unfulfilled Promise of Executive Compensation", Harvard University Press.

9. Bebchuk, Lucian and Yaniv Grinstein, (2005), "The Growth of Executive Pay", Oxford Review of Economic Policy 21:2.

10. Bertrand, Marianne and Sendhil Mullanathan, (2001), "Are CEOs Rewarded for Luck? The Ones without Principals Are", Quarterly Journal of Economics, 116:3.

11. Bertsch, Kenneth, Rachel Leahey and Hawie Haun, (1998), "The Structure and Compensation of Boards of Directors at S\&P Super 1500 Companies", Investor Responsibility Research Center.

12. Bushman Robert, Raffi Indjejikian and Abbie Smith, (1996), "Accounting Income, Stock Price and Managerial Compensation", Journal of Accounting and Economics, 21:3.

13. Campbell, John, Martin Lettau, Burton G. Malkiel and Yexiao Xu, (2001), "Have Individual Stocks Become More Volatile? An Empirical Exploration of Idiosyncratic Risk", Journal of Finance, 1:1.

14. Core, John, Robert Holthausen and David Larcker, (1999), "Corporate Governance, Chief Executive Officer Compensation, and Firm Performance", Journal of Financial Economics, 51:3. 
15. Core, John, Wayne Guay and Robert Verrecchia, (2003), "Price vs. Non-price Performance Measures in Optimal CEO Compensation Contracts", The Accounting Review, $78: 2$.

16. Eaton, Jonathan and Harvey Rosen, (1983), "Agency, Delayed Compensation and the Structure of Executive Remuneration", Journal of Finance, 38:5.

17. Garvey, Gerald and Todd Milbourn, (2006), "Asymmetric Benchmarking in Compensation: Executives are Rewarded for Good Luck But Not Penalized for Bad", Journal of Financial Economics, 82:1.

18. Gomez-Mejia, Luis Tosi and Timothy Hinkin, (1987), "Managerial Control, Performance and Executive Compensation", Academy of Management Journal, 30:1.

19. Gompers, Paul, Joy Ishii, and Andrew Metrick, (2003), "Corporate Governance and Equity Prices", Quarterly Journal of Economics, 118:1.

20. Gordon, R.A., (1940), "Ownership and Compensation as Incentives to Corporation Executives", Quarterly Journal of Economics, 54:3.

21. Grossman, Sanford and Oliver Hart, (1983), "An Analysis of the Principal Agent Problem", Econometrica, 51:1.

22. Grinstein, Yaniv and Hribar, Paul, (2003), "CEO Compensation and Incentives: Evidence from M\&A Bonuses", Journal of Financial Economics, 71:1.

23. Hadlock, Charles J. and Fee, C. Edward, (2003), "Raids, Rewards, and Reputations in the Market for CEO Talent", Review of Financial Studies, 16:4

24. Hallock, Kevin F., (1997), "Reciprocally Interlocking Boards of Directors and Executive Compensation", Journal of Financial and Quantitative Analysis, 32:3.

25. Hartzell, Jay and Laura Starks, (2003), "Institutional Investors and Executive Compensation", Journal of Finance, 58:6.

26. Hermalin, Benjamin and Michael Weisbach, (1988), "The Determinants of Board Composition", RAND Journal of Economics, 19:4.

27. Himmelberg, Charles, Glenn Hubbard and Darius Palia, (1999), "Understanding the Determinants of Managerial Ownership and the Link Between Ownership and Performance", Journal of Financial Economics, 53:4.

28. Holmstrom, Bengt, (1979), "Moral Hazard and Observability", Bell Journal of Economics, 10:1.

29. Huson, Mark, Robert Parrino, and Laura Starks (2001), "Internal Monitoring Mechanisms and CEO Turnover: A Long-term Perspective", Journal of Finance, 56:6. 
30. Jensen, Michael and Kevin Murphy, (1990), "Performance Pay and Top-Management Incentives", Journal of Political Economy, 98:2.

31. Jensen, Michael, Kevin Murphy, and Eric Wruck (2004), "Remuneration: Where We've Been, How We Got to Here, What Are the Problems, and How to Fix Them", ECGI Working Paper Series in Finance Working Paper Series, No. 44.

32. Kaplan, Steve and Bernadette Minton (2007), "How has CEO Turnover Changed? Increasingly Performance Sensitive Boards and Increasingly Uneasy CEOs", University of Chicago GSB Working Paper.

33. Kaplan, Steve and Joshua Rauh, (2008), "Wall Street and Main Street: What Contributes to the Rise in the Highest Incomes?", University of Chicago GSB Working Paper.

34. Kim, Han and Yao Lu, (2009), "Ownership and Valuation", Working Paper.

35. Lambert, Richard A., (2001), "Contracting Theory and Accounting", Journal of Accounting and Economics, 32:1.

36. Lehn, Kenneth, Sukesh Patro and Mengxin Zhao, (2003), "Determinants of the Size and Structure of Corporate Boards: 1935-2000", SSRN paper number 470675.

37. Lie, Erik, (2005), "On the Timing of CEO Stock Option Awards", Management Science, $51: 1$.

38. Lie, Erik and Randall Heron, (2007), "Does backdating explain the stock price pattern around executive stock option grants?", Journal of Financial Economics, 83:1.

39. Main, Brian, Charles O'Reilly and James Wade, (1995), "The CEO, the Board of Directors, and Executive Compensation: Economic and Psychological Perspectives", Industrial and Corporate Change, 4:2.

40. Mehran, Hamid, (1995), "Executive Compensation Structure, Ownership, and Firm Performance", Journal of Financial Economics, 38:2.

41. Manning, Willard, (1998), "The logged Dependent Variable, Heteroscedasticity and the Re-transformation Problem", Journal of Health Economics, 17:2.

42. Murphy, Kevin, (1999), "Executive Compensation", in Orley Ashenfelter and David Card (eds.), Handbook of Labor Economics, 3.

43. Murphy, Kevin and Jan Zabojnik, (2005), "Managerial Capital and the Market for CEOs", Marshall School of Business University of Southern California Working Paper.

44. Muslu, Volkan, (2003), "Board Independence, Executive Pay Structures, and Pay Disclosure: Evidence from Europe", MIT Sloan Working Paper No. 4432-03. 
45. Narayanan, M.P. and Nejat Seyhun, (2006), "The Dating Game: Do Managers Designate Option Grant Dates to Increase Their Compensation?", Ross Business School Working Paper.

46. Newman, Harry and Haim Mozes, (1999), "Does the Composition of Compensation Committee Influence CEO Compensation Practices", Financial Management, 1:1.

47. Oyer, Paul, (2004), "Why Do Firms Use Incentives That Have No Incentive Effects?", Journal of Finance, 59:4.

48. Rajgopal, Shiva, Terrence J. Shelvin, and Tina Zamora, (2006), "CEO's Outside Employment Opportunities and the Lack of Relative Performance Evaluation in Compensation Contracts", Journal of Finance, 61:4.

49. Rosenstein, Stuart, and Jeffrey G. Wyatt, (1990), "Outside Directors, Board Independence, and Shareholder Wealth, Journal of Financial Economics, 26:2.

50. Santerre, Rexford E. and Neun, Stephen P., (1986), "Stock Dispersion and Executive Compensation", Review of Economic Studies, 68:4.

51. Shivdasani, Anil and David Yermack, (1999), "CEO Involvement in the Selection of New Board Members: An Empirical Analysis", Journal of Finance, 54:5.

52. Sloan, Richard, (1993), "Accounting Earnings and Top Executive Compensation", Journal of Accounting and Economics, 16:1.

53. Tirole, Jean (2006), "The Theory of Corporate Finance", Princeton University Press.

54. Weisbach, Michael, (1988), "Outside Directors and CEO Turnover", Journal of Financial Economics, 20:2.

55. Westphal, James, (1998), "Board Games: How CEOs Adapt to Increases in Structural Board Independence from Management", Administrative Science Quarterly, 43:3.

56. Yermack, David, (1997), "Good Timing: CEO Stock Option Awards and Company News Announcements", Journal of Finance, 52:3.

57. Zajac, Eric and James Westphal, (1994), "The Costs and Benefits of Managerial Incentives and Monitoring in Large Us Corporations - When Is More Not Better", Strategic Management Journal, 15:1. 


\section{Appendix}

\section{Proofs:}

\section{Proposition 1:}

The average (or unconditional) relation between the performance measures and the compensation given by equation (5) will obtain from the average - since both states are assumed equally likely - of the compensation in state 1 given by equation (4) and the similar expression for compensation in state 2. It is easy to show that the coefficient $\Delta$ of the $\operatorname{Max}\left\{Y_{1}, Y_{2}\right\}$ term is given by:

$$
\Delta=\theta(\hat{\hat{\beta}}-\underline{\beta})=\theta(1-\delta) \frac{\lambda}{\left(1+\delta^{2}\right)+\gamma \mu \sigma^{2}} .
$$

It follows from inspection that $\Delta$ is increasing in $\theta, \lambda$ and $(1-\delta)$. Also, by taking averages of the two states and accounting for the $\operatorname{Max}()$ term, we have $\hat{\hat{\beta}}=\bar{\beta}\left(\frac{1+\delta}{2}-\frac{\theta(1-\delta)}{2}\right)$.

\section{Proposition 2:}

Let the state be $s=1$ and consider the compensation a powerful CEO expects at $t=1$, when she is choosing her effort level. If the CEO has a compromised board, she expects to receive:

$$
E(w)=\alpha_{0}+\bar{\beta} E\left(Y_{1}\right)+\underline{\beta} E\left(Y_{2}\right)+\bar{\beta}(1-\delta) E\left[\operatorname{Max}\left(0, Y_{2}-Y_{1}\right)\right]
$$

or

$$
\begin{aligned}
E(w) & =\alpha_{0}+\bar{\beta} e+\underline{\beta} \delta e \\
& +\bar{\beta}(1-\delta) \operatorname{Prob} .\left\{u_{2}-u_{1}-e(1-\delta)>0\right\} E\left[u_{2}-u_{1}-e(1-\delta) \mid u_{2}-u_{1}-e(1-\delta)>0\right]
\end{aligned}
$$

The equation above indicates the manner in which effort $(e)$ incentives for a CEO with a compromised board are affected. In state 1, the CEO expects that with some probability that the contract terms will be changed and she will receive a greater (lower) weight on the performance measure $Y_{2}\left(Y_{1}\right)$ that is less (more) affected by her effort $e$. As indicated by the negative sign on $e$ in the last term in the equation above, the possibility of the contract switch will dampen the effort incentives of a powerful CEO - relative to a CEO without power. Since the CEO without power is offered an optimal incentive contract, the powerful CEO, offered the same contract, will put in less effort and, hence, will be associated with a lower firm value. 


\section{Table I. \\ Summary Statistics}

This table reports the summary statistics of the key variables used in our analysis. CEO compensation variables are taken from Execucomp. These include salary, bonus, equity-based pay (using Black-Scholes values for option grants), other compensation, Black-Scholes volatility and CEO tenure date. In the table, we report correlation between three power measures - PowerIndex, Insider\% and \%Appointed - in Panel A. Panel B reports the firm characteristics broken into groups based on these power measures. The variables reported are asset of the firm (Assets), prior 5-year average Black-Scholes volatility (Volatility) and accounting measure of performance ( $R O A$ and a market measure of performance (Rstock). In Panel C, we report the characteristics of the CEOs in our sample. We report compensation variables (Total Compensation and Cash Compensation in '000), shareholding of the CEO (Shares Owned \%) and the years since the CEO started working in the firm (Tenure). Data in this table is for the period 1992 to 2003 . ***, ** and * denote significance at $1 \%, 5 \%$ and $10 \%$ respectively. $\dagger$ signifies differences between groups are significant atleast at $5 \%$ level.

Panel A: Correlations among Power Measures

\begin{tabular}{lccc}
\multicolumn{3}{c}{ Panel A: Correlations among Power Measures } & \%Appointed \\
\hline \hline & Power Index & Insider\% & \\
\cline { 2 - 3 } Power Index & 1 & 1 & 1 \\
Insider\% & $-0.033^{* * *}$ & $0.051^{* * *}$ & 1 \\
\%Appointed & $0.221^{* * *}$ & & \\
\hline
\end{tabular}

Panel B: Firm Characteristics

\begin{tabular}{|c|c|c|c|c|c|c|c|c|}
\hline & \multirow[t]{2}{*}{ All Firms } & \multicolumn{3}{|c|}{ PowerIndex } & \multicolumn{2}{|c|}{ Insider \% } & \multicolumn{2}{|c|}{$\%$ Appointed } \\
\hline & & Low & Medium & High & Low & High & Low & High \\
\hline Assets & 13,363 & 7,679 & 19,269 & 9,329 & 13,625 & $9,876^{\dagger}$ & 11,459 & 12,981 \\
\hline Volatility & 0.338 & 0.370 & 0.322 & 0.333 & 0.330 & $0.349^{\dagger}$ & 0.327 & $0.360^{\dagger}$ \\
\hline ROA & 4.39 & 4.27 & 4.61 & 4.16 & 4.19 & $5.21^{\dagger}$ & 4.74 & 4.41 \\
\hline RStock & 16.51 & 17.77 & 16.04 & 16.07 & 14.06 & 15.63 & 14.45 & 15.39 \\
\hline Observations & 9,460 & 2,525 & 4,258 & 2,677 & 3,730 & 3,297 & 4,378 & 2,179 \\
\hline
\end{tabular}

Panel C: CEO Characteristics

\begin{tabular}{|c|c|c|c|c|c|c|c|c|}
\hline \multirow[b]{3}{*}{ Total Compensation } & \multirow[t]{2}{*}{ All Firms } & \multicolumn{3}{|c|}{ PowerIndex } & \multicolumn{2}{|c|}{ Insider $\%$} & \multicolumn{2}{|c|}{$\%$ Appointed } \\
\hline & & Low & Medium & High & Low & High & Low & High \\
\hline & 4,472 & 3,710 & 5,308 & 3,863 & 4,476 & 4,241 & 3,627 & $6,087^{\dagger}$ \\
\hline Cash Compensation & 1,410 & 1,064 & 1,676 & 1,311 & 1,379 & $1,312^{\dagger}$ & 1,241 & $1,622^{\dagger}$ \\
\hline Shares Owned \% & 0.022 & 0.013 & 0.029 & 0.020 & 0.013 & $0.039^{\dagger}$ & 0.017 & $0.032^{\dagger}$ \\
\hline Tenure & 7.11 & 4.50 & 8.84 & 6.82 & 6.19 & $8.75^{\dagger}$ & 5.28 & $12.30^{\dagger}$ \\
\hline Observations & 9,460 & 2,525 & 4,258 & 2,677 & 3,730 & 3,297 & 4,378 & 2,179 \\
\hline
\end{tabular}




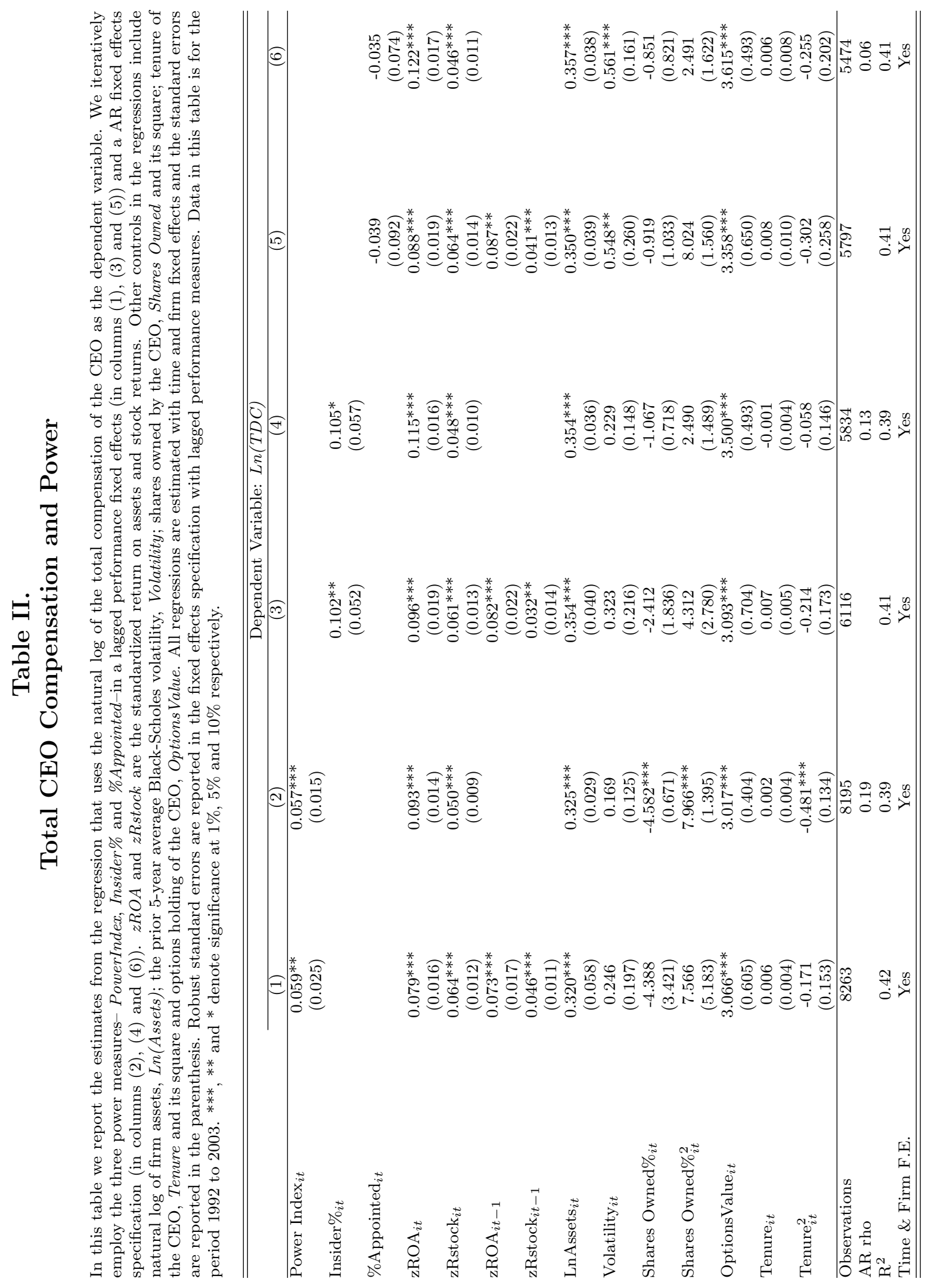




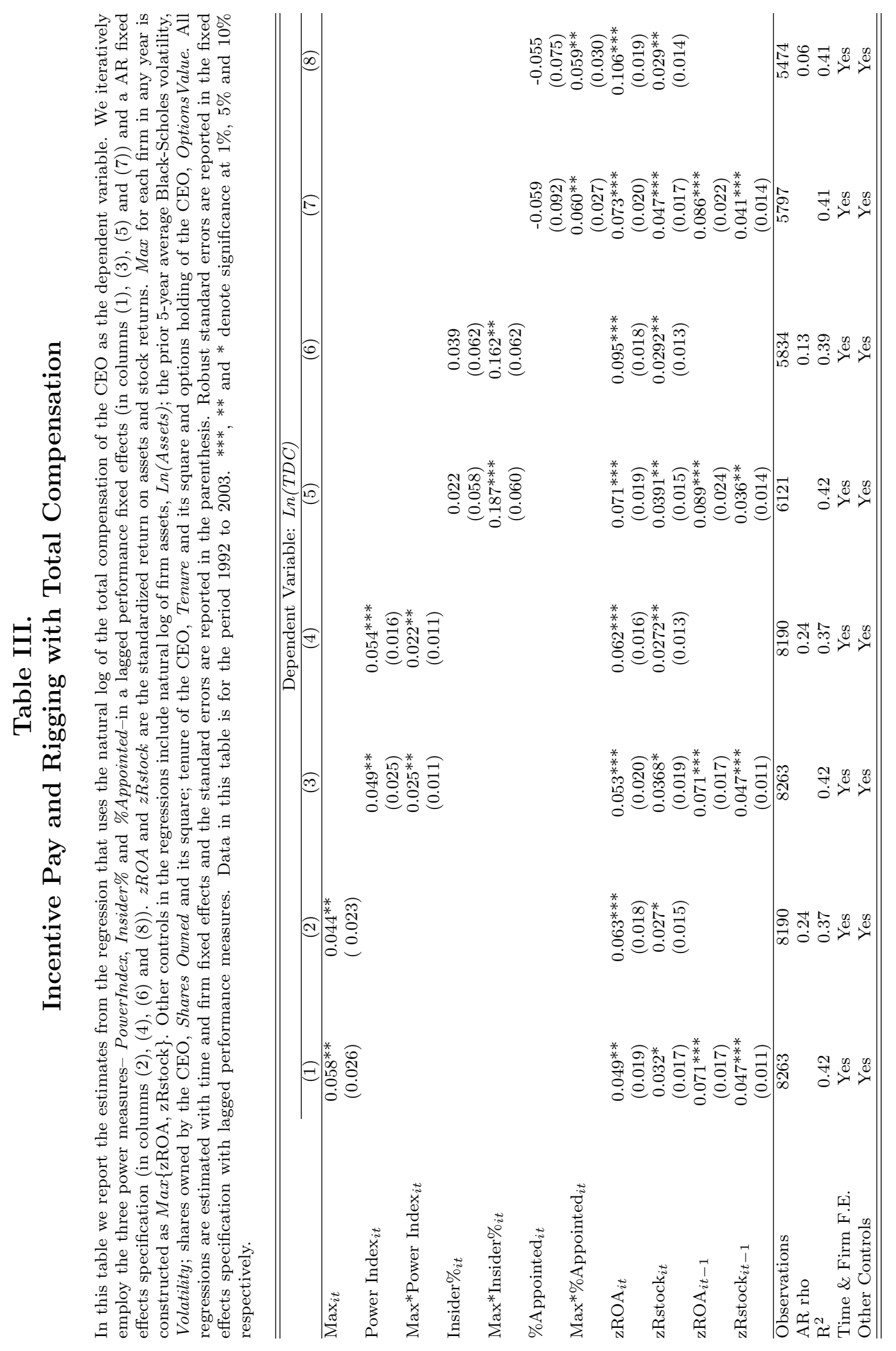




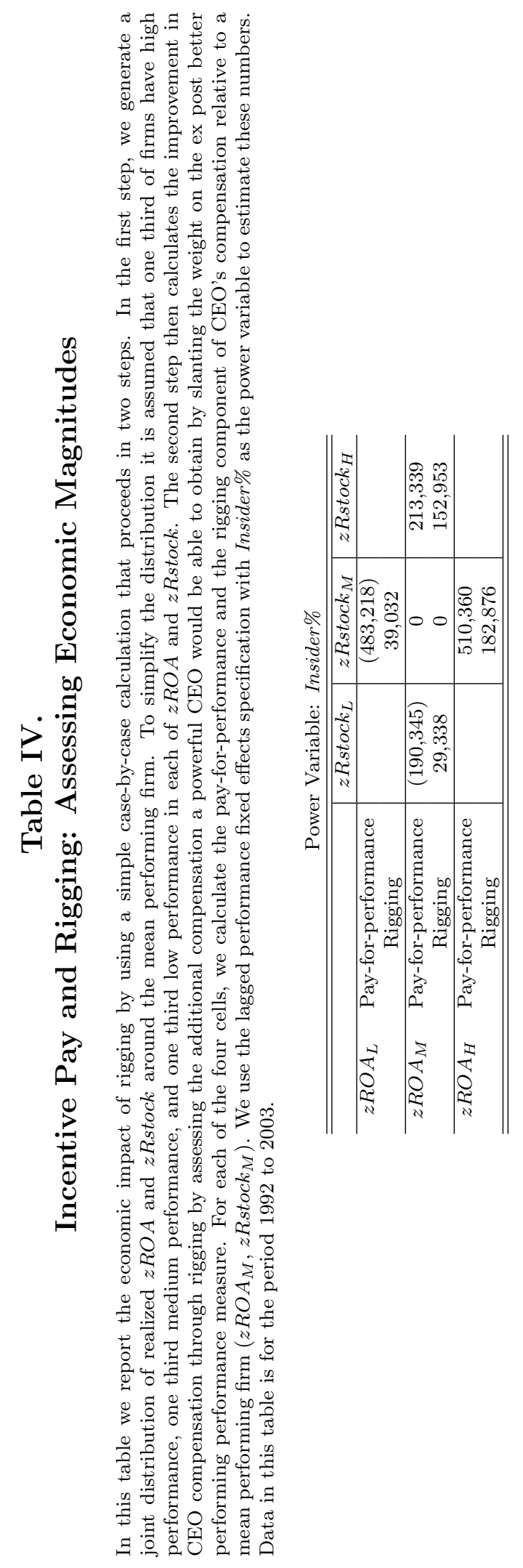




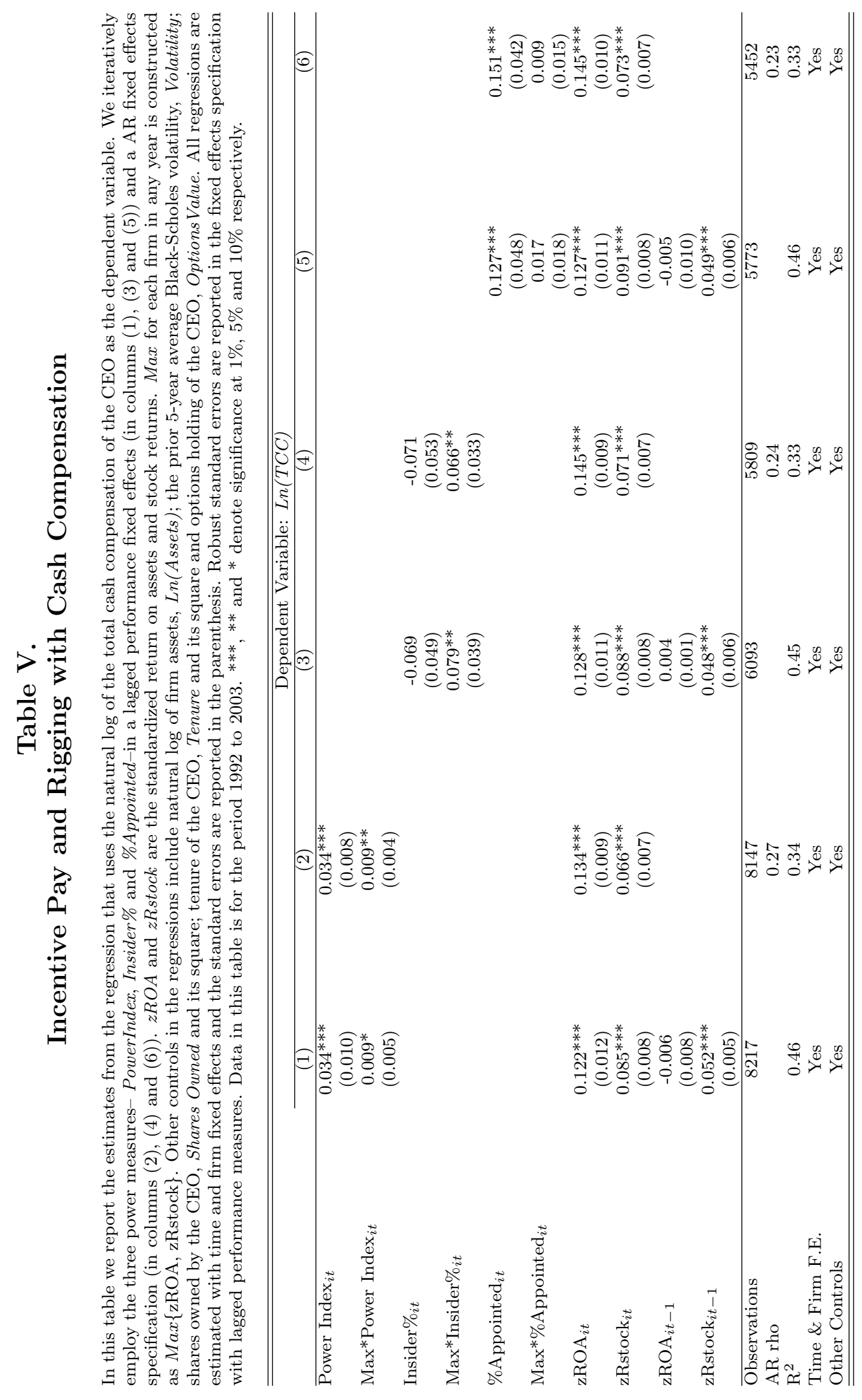




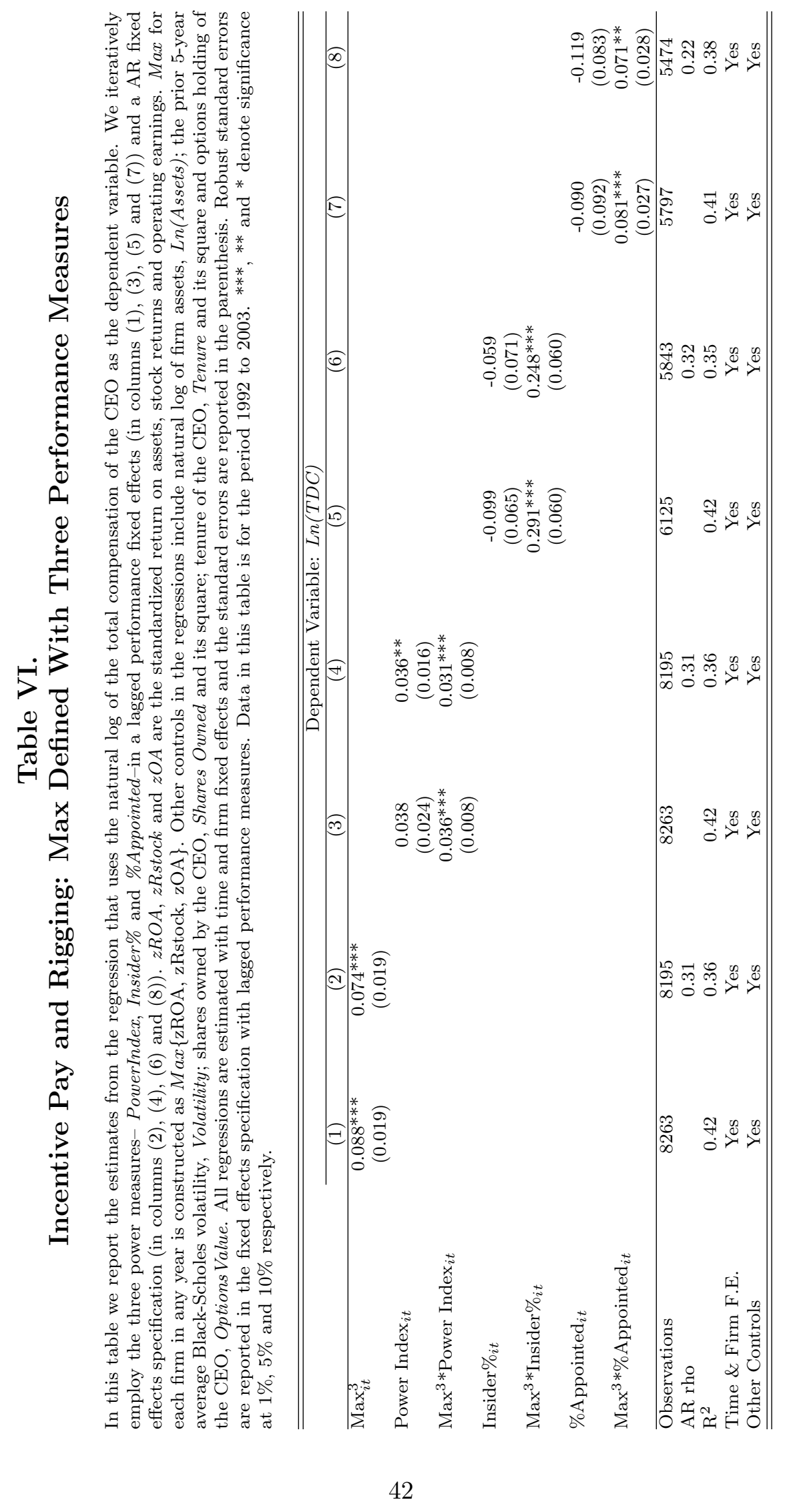



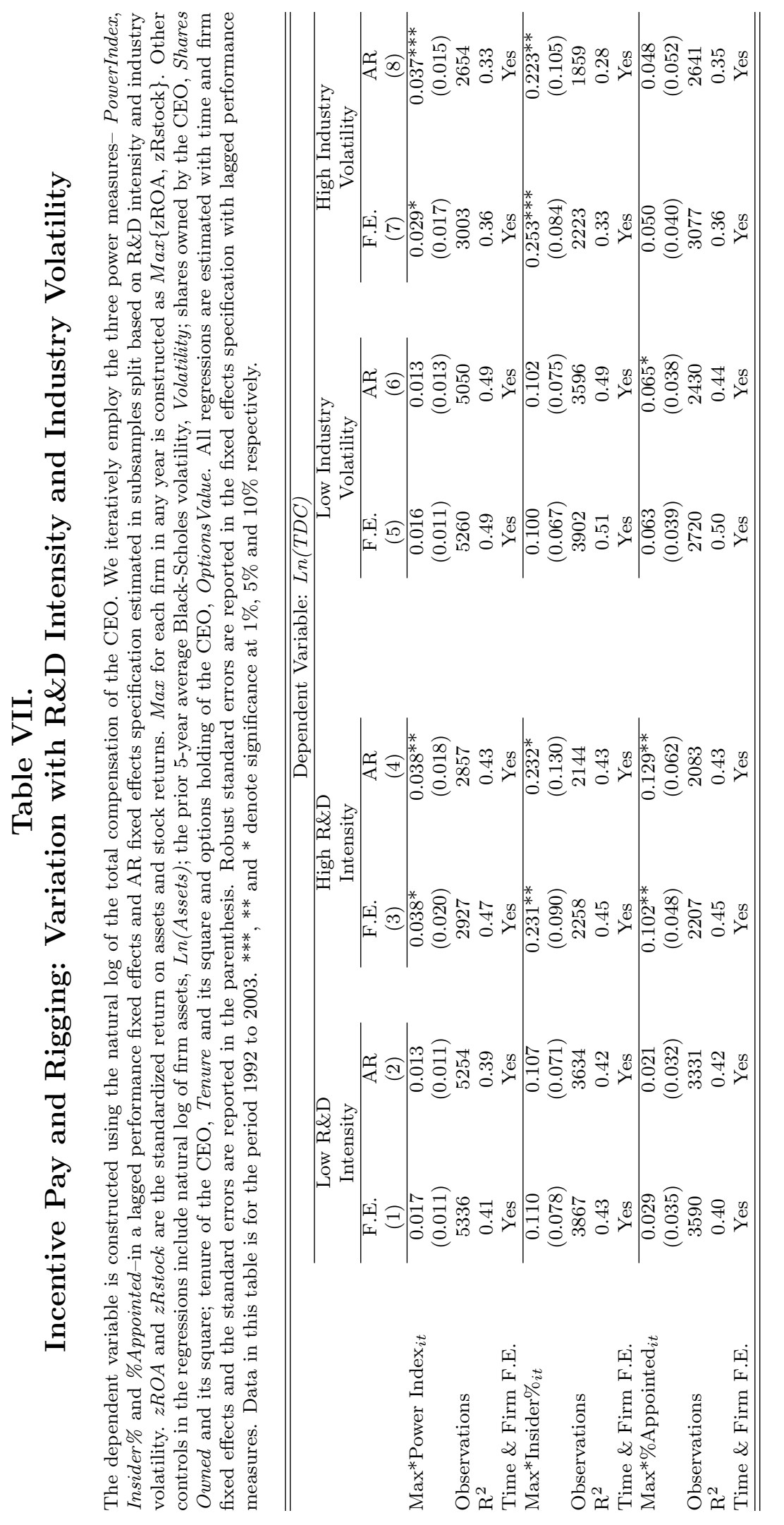


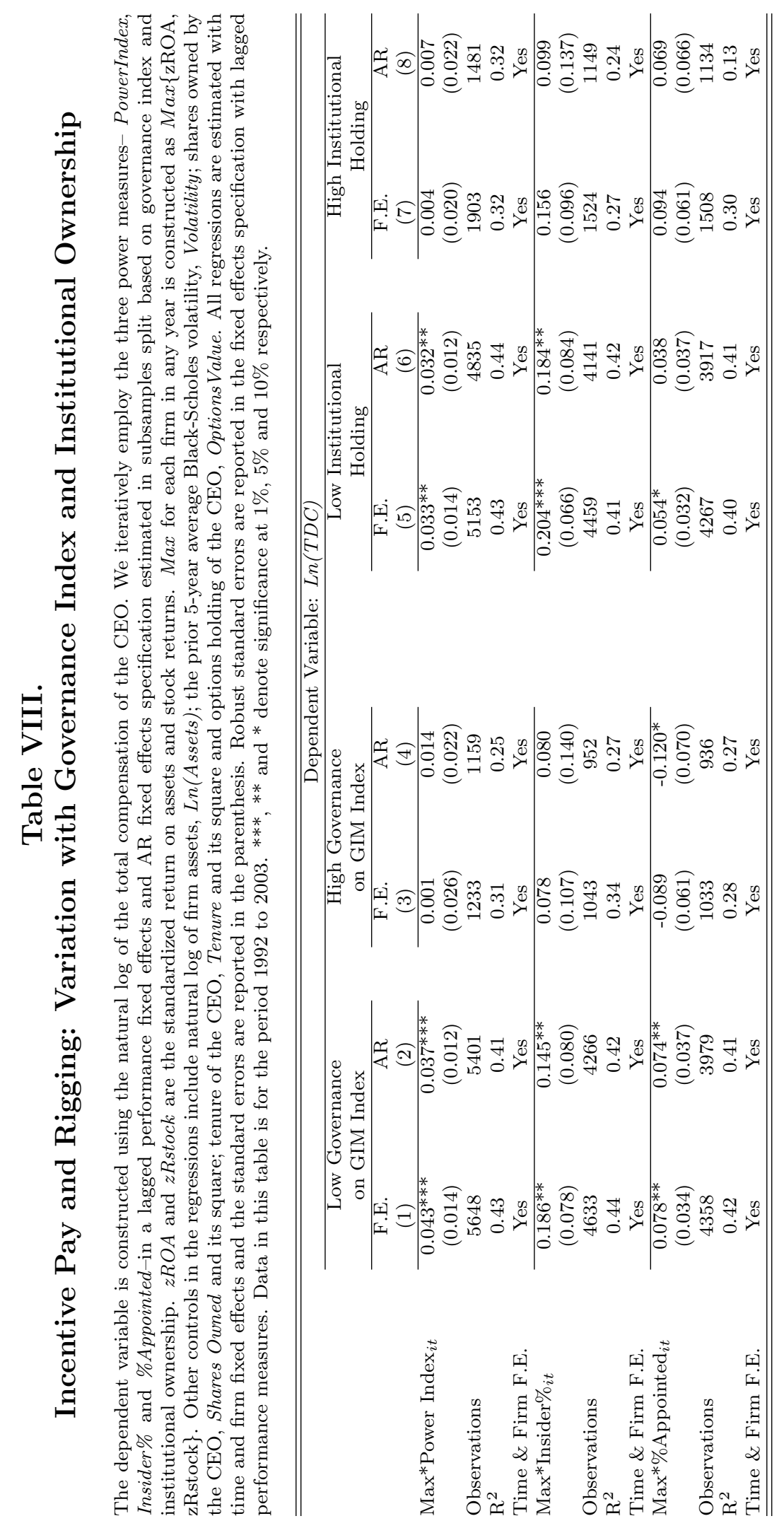




\section{Table IX. \\ Rigging and Subsequent Firm Performance}

The dependent variable is two year ahead $Q$ in Columns (1) and (2), two year ahead ROA in Columns (3) and (4) and two year ahead monthly four factor alpha in Columns (5) and (6). $Q$ is the market to book measured as the value of equity of the firm divided by the book value of equity. We compute two sets of Rigged Incentive Payit, Incentive Payit and Power Level Payit based on the estimates obtained using a specification similar to Column (3) in Table III (for FE) and using a specification similar to Column (4) in Table III (for $A R$ ). Other control variables include firm size, firm volatility, CEO holdings of stock and stock options and past annual sales growth of the firm. Firm and year fixed effects are included in all the regressions. Standard errors (reported in the parenthesis) are bootstrapped to account for generated regressors and clustered at firm level. Data in this table is for the period 1992 to 2003 . ***,** and $*$ denote significance at $1 \%, 5 \%$ and $10 \%$ respectively.

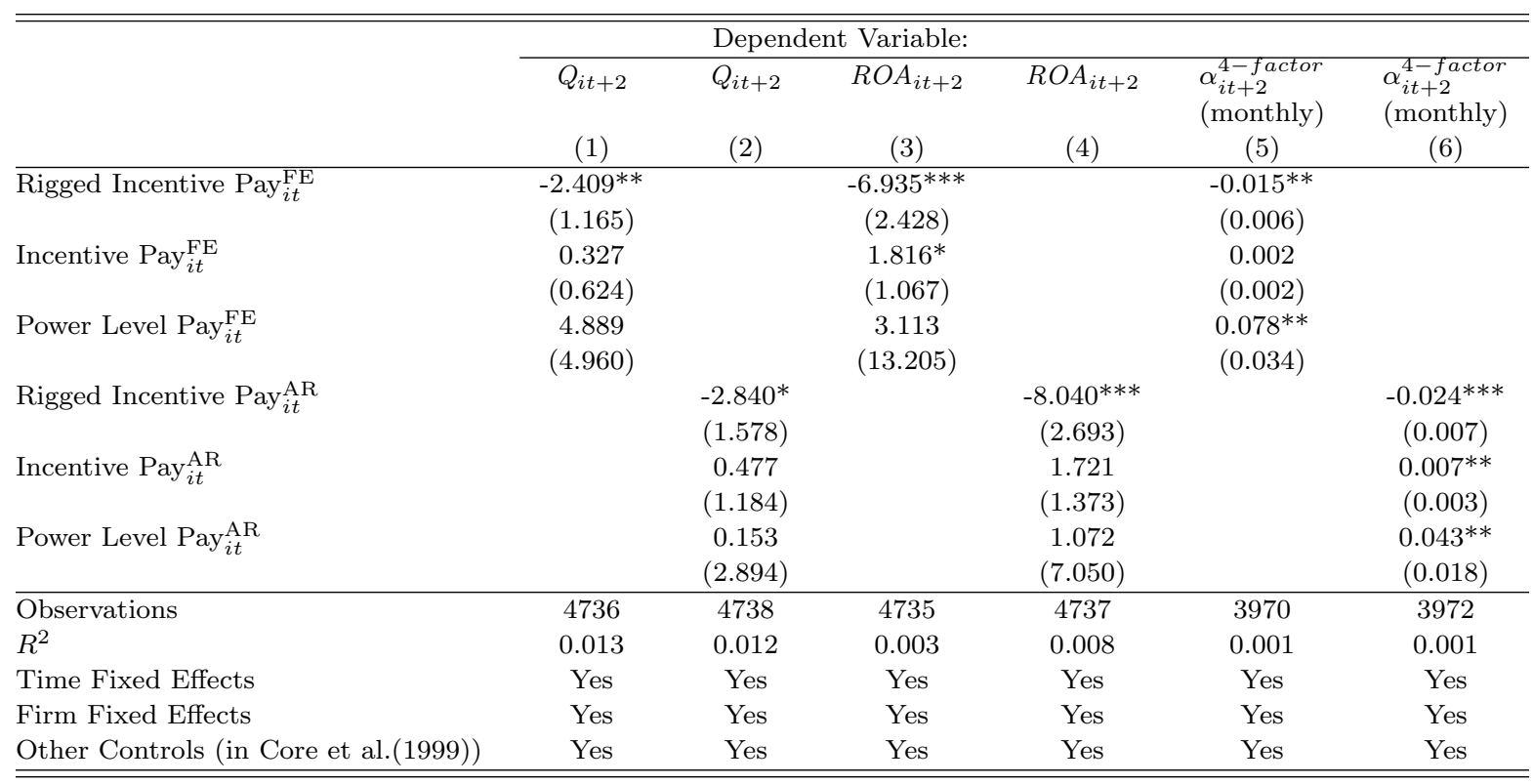



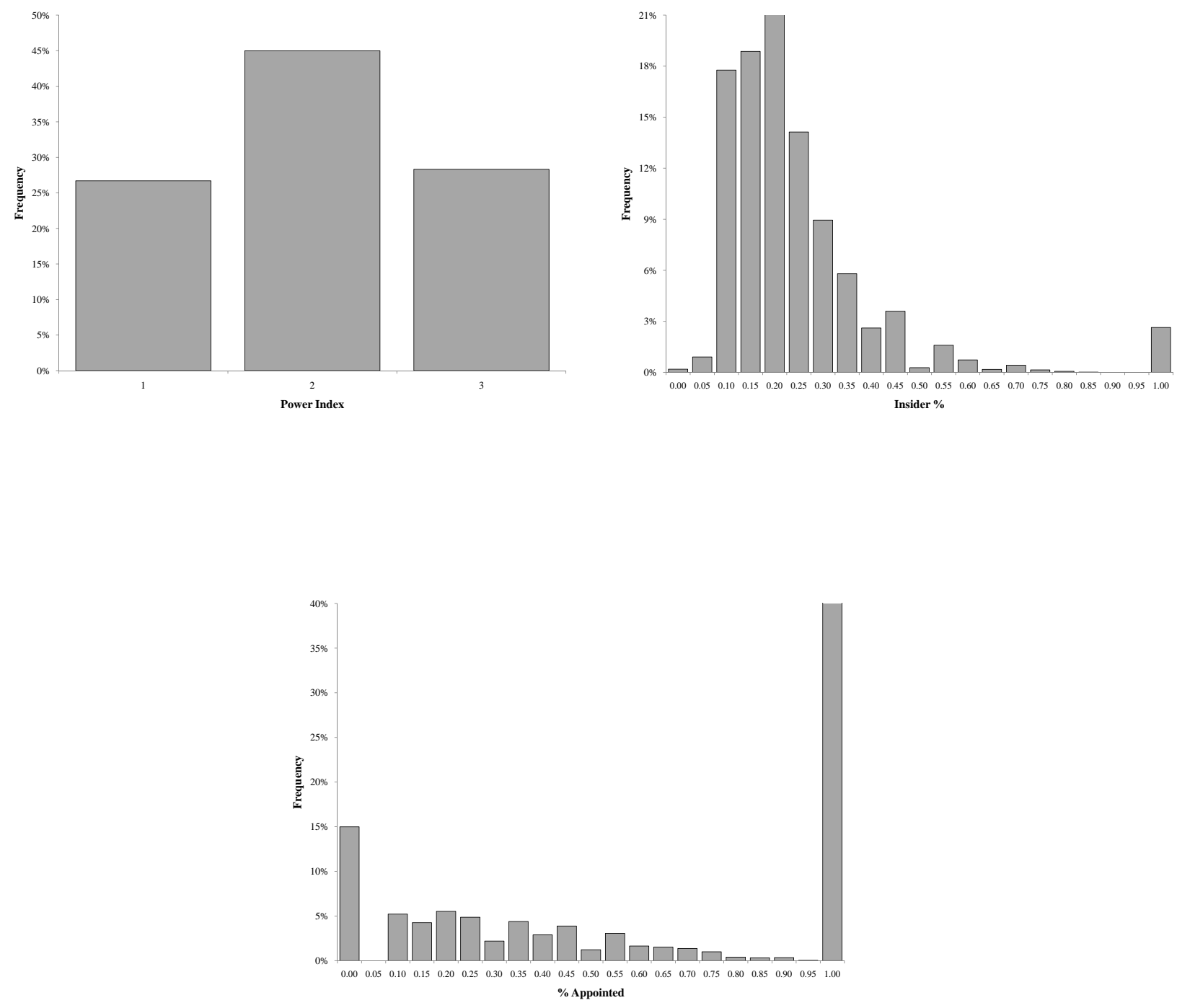

Figure 1: The figure above depicts the histograms for the power variables used in our analysis - PowerIndex, Insider \% and \% Appointed. Data used for these figures is for the period 1992 to 2003. 